\title{
MODELING EFFECTS OF TOXIN EXPOSURE IN FISH ON LONG-TERM POPULATION SIZE, WITH AN APPLICATION TO SELENIUM TOXICITY IN BLUEGILL (LEPOMIS MACROCHIRUS)
}

\author{
HUMBOLDT STATE UNIVERSITY
}

By

\author{
Michelle Gledhill
}

A Thesis

Presented to

The Faculty of Humboldt State University

\author{
In Partial Fulfillment \\ Of the Requirements for the Degree \\ Master of Science \\ In Environmental Systems: Mathematical Modeling
}

May, 2011 


\section{MODELING EFFECTS OF TOXIN EXPOSURE IN FISH ON LONG-TERM POPULATION SIZE, WITH AN APPLICATION TO SELENIUM TOXICITY IN \\ BLUEGILL (LEPOMIS MACROCHIRUS)}

\section{HUMBOLDT STATE UNIVERSITY}

By

Michelle Gledhill

Approved by the Master's Thesis Committee:

Dr. Robert Van Kirk, Major Professor

Date

Dr. Diane Johnson, Committee Member

Date

Dr. Margaret Wilzbach, Committee Member

Date

Dr. Christopher Dugaw, Graduate Coordinator

Date

Jená Burges, Vice Provost

Date

Academic Programs and Undergraduate/Graduate Studies 


\begin{abstract}
MODELING EFFECTS OF TOXIN EXPOSURE IN FISH ON LONG-TERM POPULATION SIZE, WITH AN APPLICATION TO SELENIUM TOXICITY IN BLUEGILL (LEPOMIS MACROCHIRUS)
\end{abstract}

Michelle Gledhill

A primary goal in ecotoxicology is the prediction of population-level effects of contaminant exposure based on individual-level response. Assessment of toxicity at the population level has predominately focused on the population growth rate (PGR), but the PGR may not be a relevant toxicological endpoint for populations at equilibrium. Equilibrium population size may be a more meaningful endpoint than the PGR because a population with smaller equilibrium (i.e., long-term mean) size is more susceptible to the negative effects of environmental variability. I address the ecotoxicology individual-to-population extrapolation problem with modeling. I developed and analyzed a general model applicable to many freshwater fish species that includes density-dependent juvenile survival and additional juvenile mortality due to toxicity exposure, and I quantified its effect on equilibrium population size as a means of assessing toxicity. I then used selenium toxicity in bluegill sunfish as an example to assess the effects of environmental stochasticity on toxicity response with simulation modeling. Individual-level effects are typically greater than population-level effects until the individual effect is large, due to compensatory density-dependent relationships. These effects are sensitive to the recruitment potential of a population, in particular the low-density first-year survival rate $S_{b}$. Assuming high $S_{b}$ could result in underestimating effects of population-level toxicity. The equilibrium size depends directly on $S_{b}$, the reproductive potential, the toxin concentration at which mean mortality is $50 \%\left(L C_{50}\right)$, and 
the rate at which individual mortality increases with increasing toxin concentration. More experimental data are needed to decrease the uncertainty in estimating these parameters. Effects of environmental variability resulted in simulated extinctions at much lower toxin concentrations than predicted deterministically. 


\section{ACKNOWLEDGEMENTS}

I am grateful to my committee members Dr. Robert Van Kirk, Dr. Diane Johnson and Dr. Peggy Wilzbach. It has been a great honor and pleasure to work with Dr. Rob Van Kirk on this project. Dr. Diane Johnson has been a great mentor and advisor since I was an undergraduate.

Kudos to the mathematics faculty at Humboldt State University who have been insightful in their teachings of mathematics.

To my pals who endured graduate school with me. You folks have been an integral part of this experience.

For my family: the Gledhills, Zavalas, Ariases, and Thachers. I am forever indebted to my immediate bloodline Azyadeh, Ripper and Nick Gledhill for their infinite awesomeness. I am lucky to have such a fun, wise and accepting family. Liz Silver has been exceptionally supportive throughout this graduate adventure. 


\section{TABLE OF CONTENTS}

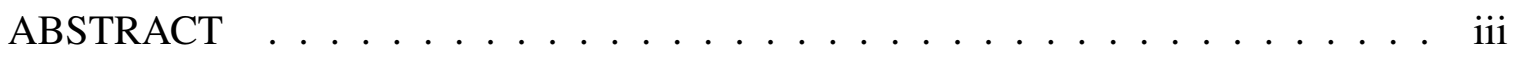

ACKNOWLEDGEMENTS ..................... . .

TABLE OF CONTENTS . . . . . . . . . . . . . . . . . . vi

LIST OF FIGURES $\ldots \ldots \ldots \ldots \ldots \ldots$. . . . . . . . . . . . . . . . . .

LIST OF TABLES $\ldots \ldots \ldots \ldots \ldots \ldots$ viii

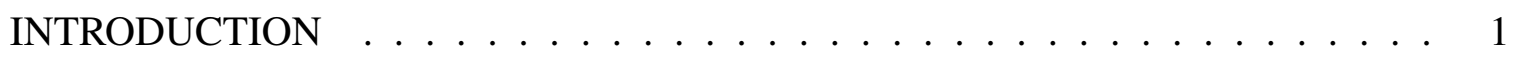

LITERATURE REVIEW . . . . . . . . . . . . . . . . . . . . . . 4

Environmental and Physiological Chemistry of Selenium . . . . . . . . . 4

Selenium Effects on Fish . . . . . . . . . . . . . . . . . . . 5

Life History and Demography of Bluegill . . . . . . . . . . . . . . . 7

Approaches to Quantifying Toxicity in Aquatic Organisms . . . . . . . . . . 9

MODEL DEVELOPMENT AND ANALYSIS . . . . . . . . . . . . . . . . 14

Framework for Development of Toxicological Population Models . . . . . . . . . 14

Demographic Model . . . . . . . . . . . . . . . . 14

Non-dimensionalization by the Equilibrium Population Size . . . . . . . . . 18

Incorporating Mortality due to Toxicity . . . . . . . . . . . . . . . . . 20

Specific form of the Toxin-Dependent Survival Function $S_{t o x}(C) \ldots$. . . 22

Deterministic Population Model for Bluegill Sunfish . . . . . . . . . . . . . 27

Stochastic Population Model for Bluegill Sunfish . . . . . . . . . . . . . . 34

Stochastic Growth . . . . . . . . . . . . . . . . . . . . . . . . . . . . . . . 34

Stochastic Survival . . . . . . . . . . . . . . 35

RESULTS AND DISCUSSION . . . . . . . . . . . . . . 37

Stochastic Results . . . . . . . . . . . . . . . . . . . . . . . . . . . . . . . 37

Effects of Environmental Stochasticity . . . . . . . . . . . . . . . . . 37

Relationship Between PGR and Equilibrium Population Size . . . . . . . . . . . 39

Relationship Between Individual-Level and Population-Level Toxicity Response . 41

Linking Population-Level Toxicity Response to Concentration . . . . . . . . . . 41

Sensitivity to $S_{b} \ldots \ldots \ldots \ldots \ldots \ldots \ldots \ldots \ldots$

Comparison with Field Data . . . . . . . . . . . . . . . . 43

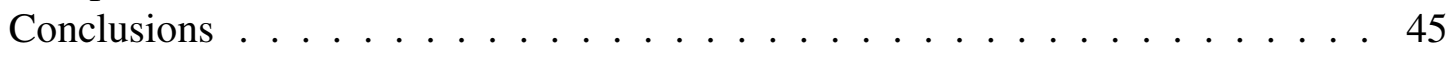

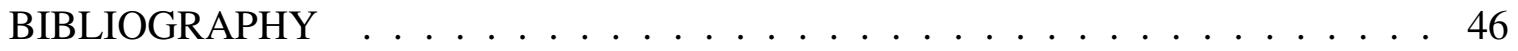




\section{LIST OF FIGURES}

Figure $\quad$ Page

1 Population-level versus individual-level toxicity effect for several values of recruitment potential $R S_{b}$. The solid line is the identity line, at which population-level effect and individual-level effect are equal. . . . . . . . 23

2 Dimensionless equilibrium population size as a function of dimensionless toxin concentration, $\tilde{E}(\tilde{C})=1-\tilde{C}^{b} /\left(R S_{b}-1\right)$, for several values of $b$ with fixed $R S_{b}=4 \ldots \ldots \ldots \ldots$. . . . . . . . . . . 26

3 Comparison of the fitted curves for the von Bertalanffy growth model. . . . 28

4 Control-adjusted survival versus whole body selenium concentration. The circles represent data from peer-reviewed studies, the thick curve is the mean survival response in Equation 24, the dashed curves bound the $95 \%$ confidence intervals, and the dotted curves bound the $95 \%$ predication in-

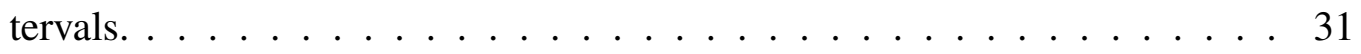

5 Persistence and extinction regions corresponding to when $\lambda=1$ and $\tilde{E}(C)=$ 0 , that is $S_{b}=1 /\left(R S_{s e}(C)\right)$. $S_{b}$ as a function of whole-body selenium concentration for $R=304.4116 \ldots \ldots \ldots \ldots$. . . . . . . . . 32

6 Bifurcation diagram depicting the stability change of $\tilde{E}(C)$ for several values of $R S_{b}$ Equation 19. The bold curves indicate that the positive nontrivial equilibrium is stable, and the dashed curves indicate that the nontrivial equilibrium becomes unstable. . . . . . . . . . . . . 32

7 Bluegill persistence and extinction regions of the dimensionless equilibrium population size, $\tilde{E}$ as a function of selenium concentration and $S_{b} . R$ is fixed at $R=304.4116 \ldots \ldots \ldots \ldots$. . . . . . . . . . 34

8 Simulation results. Each boxplot represents 1000 dimensionless population sizes after a 25 year simulation at a given concentration for $S_{b}=1, S_{b}=$ $0.5, S_{b}=0.1 \ldots \ldots \ldots \ldots \ldots$ 


\section{LIST OF TABLES}

Table

1 Fitting the von Bertalanffy growth model with different error structures. . . 28

2 Model parameters and variables for bluegill sunfish. . . . . . . . . . . . . . 29

3 Maximum Likelihood Results for the Selenium-Dependent Survival Functions. . . . . . . . . . . . . . . . . 30

4 Number of extinctions in 1000, 25 year simulations. . . . . . . . . . . 37 


\section{INTRODUCTION}

A primary goal in ecotoxicology is to predict population-level effects of contaminant exposure based on individual responses. Experimental and observational toxicity tests that address individual assessment endpoints dominate ecotoxicology literature (Walthall and Stark, 1997). Recently, however, the individual-to-population extrapolation problem has been addressed with population modeling, often in combination with observational or experimental toxicity studies (Spromberg and Meador, 2005, 2006; Van Kirk and Hill, 2007; Mebane and Arthaud, 2010). Numerous experiments assess effects of selenium toxicity to individual-level endpoints in aquatic organisms due to the increased mobilization of selenium to the environment through anthropogenic activities.

Selenium exposure has been shown to cause harmful biological effects in aquatic and terrestrial organisms (Skorupa, 1998). Two well-studied sites that experienced selenium toxicity are Kesterson Reservoir, California and Belews Lake, North Carolina. Kesterson Reservoir in the Northern San Joaquin Valley was an evaporation basin for agricultural drainwater and provided wetland habitat for fish and wildlife. In the early 1980s, the reservoir received saline drainage water and selenium concentrations exceeded $50 \mu \mathrm{g} / \mathrm{L}$ (Skorupa, 1998). Rapid die-offs of waterfowl, fish, insects and plants occured. Lemly (2002) provided evidence for severe pathological and reproductive impairment in fish from Belews Lake, North Carolina. Selenium contaminated wastewater was released from a coal-fired electric power plant from 1974 until 1986. A decade after a dry ash system was implemented, waterborne selenium concentrations were reduced to $1 \mu \mathrm{g} / \mathrm{L}$ (Skorupa, 1998). However, effects of the exposure were still apparent, revealing selenium's insidious and long-term toxicity. Effects of selenium exposure has been well documented in bluegill sunfish (Lepomis macrochirus) throughout the United States, which can act as a model 
system for analyzing population-level toxicity response.

The bluegill (Lepomis macrochirus) is a standard laboratory test species that has been shown to be sensitive to selenium exposure in laboratory experiments (Lemly, 1985; Gillespie and Baumann, 1986; Woock et al., 1987; Hermanutz et al., 1992; Besser et al., 1993; Coyle et al., 1993; Lemly, 1993b; McIntyre et al., 2008) and in the wild (Finley, 1985; Skorupa, 1998; Lemly, 2002). The bluegill is an important species for recreational fishing and is often stocked to provide food for largemouth bass (Micropterus salmoides), another important game fish. Past approaches to assessing toxicity in bluegill consisted of experimental assays that analyzed the effect of increased selenium tissue concentrations on survival, growth, reproductive success and teratogenesis (Cardwell et al., 1976; Gillespie and Baumann, 1986; Woock et al., 1987; Hermanutz et al., 1992; Cleveland et al., 1993; Coyle et al., 1993; Lemly, 1997). Lemly (1993b) and McIntyre et al. (2008) observed an increase in selenium toxicity to bluegill at reduced water temperatures that mimicked winter conditions.

A goal of this thesis is to address the ecotoxicology individual-to-population extrapolation problem with modeling. Given individual-level toxicity response, I seek to develop a general model to predict a population-level response in freshwater fish, using bluegill as an example. This thesis first reviews the environmental chemistry of selenium, the demography of bluegill, and past approaches used to quantify effects of selenium exposure on bluegill. The methods sections includes analysis of an age-structured, analytical differenceequation model with a non-linear function describing density-dependent juvenile mortality, a fit of model parameters to specific data on selenium and bluegill, and a simulation model that incorporates environmental variability. Objectives of this thesis are: (1) to develop and analyze a general model applicable to many different species of freshwater fish that includes density-dependent juvenile survival and additional juvenile mortality due to toxi- 
city exposure, (2) quantify response in equilibrium population size as a means of assessing toxicity, and (3) assess effects of environmental stochasticity on toxicity response, using the bluegill-selenium model system. 


\section{LITERATURE REVIEW}

\section{Environmental and Physiological Chemistry of Selenium}

Selenium (Se) is a naturally occurring element found in depositional and sedimentary geologies. The worldwide release of selenium is about 14,700 metric tons/year, of which $43 \%$ is from anthropogenic sources (Nriagu, 1989). Erosion and deposition of selenium in the environment have been accelerated by anthropogenic activities such as coal mining and agriculture, which can locally pose great hazards to fish and wildlife (Eisler, 1985; Skorupa, 1998). For example, many wetlands in the western United States have been impacted by contaminated irrigation drainwater (Zhang and Moore, 1998), which is a mixture of surface return flows and subsurface drainage (Saiki et al., 2001). Drainwater contains elevated concentrations of selenium through the accumulation of solubles and evaporation, particularly in arid regions. Soil drainage problems typically arise in areas with a relatively impermeable layer of clay below the soil surface where saline groundwater accumulates without adequate drainage (Saiki and May, 1988).

Internal recycling of selenium among biota, sediments, and water contribute to accumulation above known toxicity thresholds (Lemly, 1985, 1993c; Besser et al., 1996). Shortterm selenium inputs can lead to long-term residual exposure of biota (Skorupa, 1998; Lemly, 1999). For instance, although waterborne selenium concentrations were reduced to less than $1 \mu \mathrm{g} / \mathrm{L}$ a decade after a dry ash disposal system was implemented in Belews Lake (Lemly, 1997), sediment, invertebrates, and fish ovary concentrations were still moderately elevated (Skorupa, 1998). Efficient recycling of selenium in the biotic pathways also occurred in a power plant cooling basin in Martin Reservoir, Texas and Kesterson Reservoir, California (Skorupa, 1998).

Selenium is a necessary micronutrient for aquatic organisms at low concentrations but 
becomes toxic above certain threshold concentrations (Cleveland et al., 1993). For example, dietary requirements of selenium in fish range from $0.07 \mu \mathrm{g} / \mathrm{g}$ dry weight in rainbow trout (Oncorhynchus mykiss) (Hilton et al., 1980) to $0.25 \mu \mathrm{g} / \mathrm{g}$ in channel catfish (Ictalurus punctatus) (Gatlin and Wilson, 1984). By comparison, selenium concentrations in fish from waters in the San Joaquin Valley ranged from $0.6-18 \mu \mathrm{g} / \mathrm{g}$ (Saiki et al., 2001). Rotruck et al. (1973) showed that selenium is an essential micronutrient and a necessary component in glutathione peroxidase. Selenium is an important antioxidant that assists in the prevention of several disease conditions. Several selenoproteins have been identified and appear to be genetically controlled, but their biological functions are unknown (Maas, 1998). However, at high concentrations, chemical similarities between selenium and sulfur can be problematic during protein synthesis. Substitution of selenium for sulfur can result in a distortion of protein building blocks and teratogenesis (Lemly, 1998). According to Raisbeck (2000), the primary targets of acute selenium toxicity in food animal species are the cardiovascular and gastrointestinal systems. The primary impact on bluegill is in the reproductive system (Coyle et al., 1993).

\section{Selenium Effects on Fish}

Contaminant levels in aquatic organisms are of considerable interest due to their potential

effects on the organisms themselves as well as on the surrounding ecosystems. Elevated selenium concentrations have been associated with individual and population-level effects in many species of fish, including bluegill sunfish (Cardwell et al., 1976; Finley, 1985; Gillespie and Baumann, 1986; Woock et al., 1987; Hermanutz et al., 1992; Cleveland et al., 1993; Coyle et al., 1993; Lemly, 1993b; Besser et al., 1996; Lemly, 2002; Swift, 2002; McIntyre et al., 2008). Metabolic stress during winter conditions has been shown 
to increase the toxicity of selenium by significantly increasing mortality rates of bluegill exposed to waterborne and dietary selenium (Lemly, 1993b; McIntyre et al., 2008). Hermanutz et al. (1992) reported that 10 waterborne $\mu \mathrm{g} \mathrm{Se} / \mathrm{L}$ reduced survival of bluegill populations in outdoor experimental stream treatments with water temperatures above $4^{\circ} \mathrm{C}$. Reproductive failure, in which selenium accumulates in the egg and and post-hatch mortality is increased, is a symptom of selenium poisoning (Coyle et al., 1993; Lemly, 2002). Acute and chronic exposure to selenium can result in population declines in short amounts of time as a result of complex juvenile stage dynamics and selenium's insidious mode of toxicity.

Researchers studying selenium contamination in Belews Lake, North Carolina identified a threshold of 2-5 $\mu \mathrm{g} / \mathrm{L}$ of waterborne selenium for fish, which resulted in the Environmental Protection Agency (EPA) revising the national chronic criterion for selenium from 35 to $5 \mu \mathrm{g} / \mathrm{L}$ in 1987 (USEPA, 1987; Skorupa, 1998; USEPA, 2006). In natural environments, fish are exposed to varying concentrations of selenium due to the fish's ability to move in and out of areas of high concentrations, so an average aqueous concentration may not adequately identify concentrations the fish experiences (Hermanutz et al., 1992). Recent studies continue to support a dietary selenium threshold of $3 \mu \mathrm{g} / \mathrm{g}$ and a whole-body selenium threshold of $4 \mu \mathrm{g} / \mathrm{g}$ for fish (Hamilton, 2003). In the experiments conducted by Cleveland et al. (1993) to assess the bioaccumulation of selenium during dietary and aqueous exposures, bluegill did not bioaccumulate concentrations higher than those in their test diets. Coyle et al. (1993); Cleveland et al. (1993) and Besser et al. (1993, 1996) agreed that selenium accumulation is primarily derived from dietary sources rather than aqueous selenium exposure. Thus, toxicity hazards to fish and wildlife are more appropriately expressed as tissue selenium concentrations in the species of interest, or their prey, rather than as aqueous concentrations (Besser et al., 1993; Lemly, 1993a; Besser et al., 1996; Skorupa, 
1998).

Selenium has been reported to reduce growth or condition factor in Chinook salmon (Onchorhynchus tshawytscha) (Hamilton et al., 1986; Hamilton and Wiedmeyer, 1990), fathead minnow (Pimephales promelas) (Bennett et al., 1986; Ogle and Knight, 1989), and rainbow trout (Onchorhynchus mykiss) (Hilton et al., 1980). Cleveland et al. (1993) showed a significant reduction in condition factor in bluegill as a function of whole body selenium concentration. Nakamoto and Hassler (1992) observed reduced length of yearling bluegill in a stream with a higher selenium concentration compared to fish from a nearby stream. No difference in growth rate was observed for bluegill of ages 2 - 4 years, suggesting that selenium may affect growth primarily during first growing season. Coyle et al. (1993); Lohner et al. (2001); McIntyre et al. (2008) reported no response of selenium on growth rate of bluegill.

Selenium toxicity to bluegill has been well documented throughout the United States (Skorupa, 1998). The bluegill is a standard laboratory test species and have been been shown to be sensitive to selenium exposure (Lemly, 1985; Gillespie and Baumann, 1986; Woock et al., 1987; Hermanutz et al., 1992; Besser et al., 1993; Coyle et al., 1993; Lemly, 1993b; McIntyre et al., 2008).

\section{Life History and Demography of Bluegill}

The bluegill (Lepomis macrochirus) is a warmwater sunfish (family Centrarchidae). They occupy slow-moving water and are endemic to North America (Moyle, 2002), though they have been widely introduced outside their native range. Their bodies are laterally compressed, and they feed primarily as invertivores and piscivores. Typical size of bluegill is 200-250 mm total length, but they can grow up to $410 \mathrm{~mm}$ total length (Page and Burr, 
1991). The maximum recorded age of bluegill was twelve years (Paukert et al., 2001), although the typical life span is 3-7 years (Belk, 1995).

Bluegill exhibit elaborate social structures and considerable variation in life-history characteristics (Aday et al., 2002). This plasticity of life-histories is mainly due to environmental influences, such as resource availability and size-specific predation, rather than to genetic contributions (Belk, 1995; Aday et al., 2002). Age-at-maturity is tightly coupled with size-at-maturity, which is a critical determinant of female fecundity and reproductive success for males (Belk and Hales Jr., 1993). As sexual maturation is energetically expensive, little growth occurs once bluegill mature, as energy is diverted from somatic growth into gonadal development and reproductive activities (Edison et al., 2006).

In their native range, bluegill spawn in nesting colonies (Gross and Macmillan, 1981) typically from May to August; nests and eggs are usually first observed around mid-to-late May (Garvey et al., 2002). Fry begin to emerge in late May and early June (Breck, 1996), and most hatch from mid-June to mid-July (Garvey et al., 2002). Parental males exhibit care for their eggs and nest, resulting in high egg-to-fry survival rates (Bain and Helfrich, 1983). Some males exhibit an alternative reproductive strategy in which they are known as "satellites" or "sneakers." Satellite and sneaker males mature precociously and do not build nests of their own but mimic females or use sneaking, respectively, to gain access to fertilization during oviposition (Belk and Hales Jr., 1993; Breck, 1996; Neff et al., 2003). Many factors affect bluegill reproductive success, including predation risk, body size, hatch date, temperature, physical habitat, resource availability and competition for food and first winter survival (Santucci, Jr. and Wahl, 2003; Gosch et al., 2006).

Resource and habitat limitations will influence survival, growth and fecundity in density dependent populations (Spromberg and Meador, 2005). Breck (1996) showed that recruitment failure, or year-class failure occurs early in the summer during spawning, hatching, 
and swim-up in stocked ponds. The mechanisms for year-class failure do not appear to be starvation or overwinter mortality. A substantial mechanism producing recruitment failure in density-dependent bluegill populations is cannibalism by juveniles (age-1 and age-2) on eggs, larvae, and fry (Breck, 1996). Furthermore, high densities of juveniles $(16.8 \mathrm{~kg} / \mathrm{ha}$ age-1 and $78 \mathrm{~kg} / \mathrm{ha}$ of age-2) were shown to prevent recruitment primarily by means of cannibalism, and $30 \mathrm{~kg} / \mathrm{ha}$ of age- 2 individuals resulted in only moderate abundance of fry.

\section{Approaches to Quantifying Toxicity in Aquatic Organisms}

Classical approaches to quantifying toxicity response consist predominately of experimental assays measuring effects of elevated dietary, waterborne and whole-body toxin concentrations to individual assessment endpoints such as survival, growth, reproductive success, condition factor, or teratogenesis. Assessment at the population level has generally been based on these single, individual-level endpoints (Forbes et al., 2000) by implementing a diversity of analysis of variance (ANOVA) models to analyze experimental and observational toxicity data (Cardwell et al., 1976; Gillespie and Baumann, 1986; Woock et al., 1987; Hermanutz et al., 1992; Besser et al., 1993; Cleveland et al., 1993; Coyle et al., 1993; Lemly, 1993b; Besser et al., 1996; Lemly, 1997). However, toxicity impacts at the population level may not correlate with individual toxicity responses. For instance, major impacts on individuals may be insignificant at the population level (Ferson et al., 1996). Also, negligible impacts on individuals can sometimes cascade through population dynamics into significant impacts at the population and ecosystem-level (Ferson et al., 1996). There is no consistency in how accurately individual-level effects can predict population-level outcomes (Stark, 2005).

The most common population-level measure of toxicity is its effect on the popula- 
tion growth rate (PGR), which can be expressed as the continuous growth rate $r$ per unit time, or by the discrete multiplicative rate, $\lambda$, where $\lambda=e^{r}$ (Hansen et al., 1999; Stark and Danken, 1999; Forbes et al., 2000; Kuhn et al., 2000; Stark and Vargas, 2003; Stark, 2005). Forbes and Calow (1999) concluded that the PGR is a better response variable than individual-level endpoints, such as condition factor or fecundity, since $r$ explicitly integrates individual-level responses to contaminants at the population level. Hansen et al. (1999) performed sensitivity analyses of the PGR with respect to changes in life-history traits of the polycheate Capitella. Similarly, Forbes et al. (2000) analyzed the elasticity of the PGR with respect to life cycle variables in a semelparous benthic macroinvertebrate, an iteroparous fish, a daphnid, and an algal species.

Walthall and Stark (1997) distinguished between the intrinsic and instantaneous rates of population growth, $r_{m}$ and $r_{i}$ respectively. Here, $r_{m}$ can be solved for by the following Euler-Lotka equation

$$
1=\sum_{k=0}^{n} l_{k} m_{k} e^{-r_{m} k},
$$

where the summation is over the discrete ages, $k$, of the cohort to a maximum age $n, l_{k}$ is the proportion of individuals surviving to age $k$, and $m_{k}$ is the number of mature females produced per female of age $k$. Thus, $r_{m}$ measures the theoretical ability of a population to increase exponentially in an unlimited environment, as defined in Lincoln et al. (1982). It is standard to assume a $50 \%$ sex ratio by letting $m_{k}=1 / 2$ to count females only, but this assumes that the proportion of females in each age class is invariant (Forbes and Calow, 1999). The instantaneous rate of change measures the ability of a population to increase exponentially at any given time, regardless of density (Lincoln et al., 1982), and is given by

$$
r_{i}=\lim _{\Delta t \rightarrow 0} \frac{\ln \left(N_{t+\Delta t} / N_{t}\right)}{\Delta t},
$$


where $N_{t}$ is the number of individuals at time $t$ and $N_{t+\Delta t}$ is the number of individuals at the subsequent time step, $t+\Delta t$.

Absent in toxicology literature is evidence indicating whether the PGR is the best endpoint in assessing toxicity response at the population-level. Forbes and Calow (1999) note that most experimental work has considered $r$ to be be positive, indicating that the population is growing, but for most natural populations, the instantaneous growth rate $r$ must tend to zero (Calow et al., 1997; Forbes and Calow, 1999), and thus $\lambda$ must tend to one in the long-term. That is, most populations exist at or near a long-term equilibrium value, at which the instantaneous growth rate is zero by definition (Equation 1). Dennis and Taper (1994) showed that density-dependent populations exist at a stochastic equilibrium, i.e. at a probability distribution of abundance that remains fixed over time (Allen, 2003). Thus, between the two types of growth rates, the intrinsic growth rate is the only meaningful measure of effect of toxicity on the population's growth rate. Hence, from here on, I use "PGR" to denote the intrinsic growth rate. However, even if effects of toxicity are measured by changes in the intrinsic growth rate, impacts on the long-term population size may be a more revealing toxicological endpoint than impacts on PGR. Investigating both endpoints simultaneously could be advantageous, particularly with regards to environmental stochasticity. For instance, the PGR is not likely to be a relevant toxicological endpoint where contaminant exposure reduces equilibrium population size to low abundances and thereby increases probability of extinction due to random events.

To illustrate how increased mortality can alter both the equilibrium size and PGR, consider the simplest density-dependent population model, the logistic model. The continuous logistic model of population size $u(t)$ as a function of time is

$$
\frac{d u}{d t}=f(u)=r u\left(1-\frac{u}{K}\right),
$$


where the PGR is $f^{\prime}(0)=r>0$, and the constant external habitat capacity is $K$ (EdelsteinKeshet, 2005). Equation 2 has an unstable equilibrium at $u^{*}=0$ and a stable equilibrium at $u^{*}=K$. Applying a simple linear stressor $\alpha u$ representing additional mortality, where $\alpha<r$, to the logistic model in Equation 2 yields

$$
\frac{d u}{d t}=g(u)=r u\left(1-\frac{u}{K}\right)-\alpha u
$$

Equation 3 has an unstable equilibria $u^{*}=0$, and a stable equilibrium at $u^{*}=K(1-\alpha / r)$ when $\alpha<r$. As expected, the PGR of Equation $3 g^{\prime}(0)=r-\alpha$ is decreased, but also the equilibrium population size, $K(1-\alpha / r)$, is now a fraction $1-\alpha / r$ of the environmental carrying capacity $K$. Notice that both the PGR and the equilibrium size indicate population persistence if $r$ exceeds $\alpha$. But by solely analyzing the PGR to assess a population-level toxicity response, we would overlook that the population size has been reduced, and a smaller population size is more susceptible to the effects of environmental variability. Even a simple model shows that additional mortality can affect both the PGR and the equilibrium size.

This example illustrates how population modeling can be used to calculate populationlevel effects of toxicity, whether they are measured by PGR, equilibrium size or both. Population modeling has not been extensively applied to toxicology (but see Spromberg and Meador, 2005; Spromberg and Birge, 2005; Spromberg and Meador, 2006; Van Kirk and Hill, 2007; Mebane and Arthaud, 2010), and population-level endpoints predominantly consist of analyzing effects on the PGR $(\lambda$ or $r$ ) of the species of interest. Furthermore, few toxicological studies have included environmental variability (but see Van Kirk and Hill, 2007; Mebane and Arthaud, 2010), which affects population viability (Goodman, 1987; Dennis et al., 1991). Ferson et al. (1996) agrees that any toxicity assessment must in- 
clude natural variability to claim ecological relevance. Forbes and Calow (1999) noted that most experimental work does not include density-dependent effects, which may intensify or mitigate the effects of contaminants at the population level. To my knowledge, most ecotoxicological population models have been linear; Spromberg and Birge (2005); Spromberg and Meador (2005, 2006); Van Kirk and Hill (2007) and Mebane and Arthaud (2010) are the only authors to include nonlinearities in toxicological population models.

In the next chapter, I develop a discrete time, age-structured model that represents the life-history, demography and reproduction schedules of many freshwater fish species. Furthermore, I use stochastic models to analyze the effects of reduced population size and density-dependent juvenile survival, extrapolating to population-level response based on individual toxicity. 


\section{MODEL DEVELOPMENT AND ANALYSIS}

In this section, I provide a general framework for the development of a demographic model that aids in assessment of toxin exposure to freshwater fish. I then apply this framework to investigate bluegill population response to selenium based on individual-level toxicity by parameterizing the model with data specific to the bluegill-selenium system. Deterministic and stochastic versions of the model are used to investigate effects of selenium exposure on the equilibrium population size.

\section{Framework for Development of Toxicological Population Models}

\section{Demographic Model}

Most freshwater fish spawn once every year and populations can be efficiently described with difference equations in which the time units are years. As is standard in demographic modeling, the model tracks only females. Let $x_{j}$ be the number of females in age class $j$ with maximum age $n$, and let $x_{0}$ be the number of emergent fry. Let $S_{j}$ be the annual survival rate from age class $j-1$ to $j$, and because competition for limited and heterogeneously distributed resources generally influences juvenile stages (DeAngelis et al., 1980), let $S_{1}\left(x_{0, t}\right)$ be a density-dependent juvenile survival function that possesses the following properties: $0<S_{1}\left(x_{0, t}\right) \leq 1, \lim _{x_{0} \rightarrow \infty} S_{1}\left(x_{0, t}\right)=0$, and $\lim _{x_{0} \rightarrow 0} S_{1}\left(x_{0, t}\right)=S_{b}$, where $0<S_{b} \leq 1$ is the baseline first-year survival rate, that is, the survival rate in absence of density-dependent effects. Under the classical contest competition model (Henle et al., 2004),

$$
S_{1}\left(x_{0, t}\right)=\frac{S_{b}}{1+\alpha x_{0, t}}
$$


where $\alpha=S_{b} / K$ and $\mathrm{K}$ is the carrying capacity of age 1 fish. The carrying capacity of the whole population can be related to $\alpha$ as will be demonstrated below. $S_{1}\left(x_{0, t}\right)$ leads to the classical Beverton-Holt stock-recruitment model if there is no age-structure, that is, $x_{t+1}=S_{1}\left(x_{t}\right) x_{t}$, where $\alpha=(\lambda-1) / K, K$ is the population carrying capacity, and $S_{b}=\lambda$ is the intrinsic finite growth rate (Haddon, 2001).

This is similar to, but not mathematically equivalent to, the modified Beverton-Holt recruitment model that Spromberg and Meador $(2005,2006)$ implemented to describe juvenile density-dependent survival rates in salmon populations. In their model, first-year survival $S_{1}$ is given by

$$
S_{1}\left(x_{0, t}\right)=\frac{1-b_{m}}{1-b_{m}\left(1-\frac{x_{0, t}}{x_{1, \max }}\right)}
$$

where $b_{m}$ is the "baseline mortality" (Spromberg and Meador, 2006, p. 245) for age 0, $x_{1, \max }$ is the "maximal capacity of age 1" (Spromberg and Meador, 2006, p. 245) individuals, and $t$ is time in years. Equation 5 describes a concave monotonically decreasing relationship between first-year survival and age 0 abundance. The abundance, $x_{1, t+1}$, of age- 1 juveniles at the subsequent time step is then given by $x_{1, t+1}=S_{1}\left(x_{0, t}\right) x_{0, t}$. The dependence of $x_{1, t+1}$ on $x_{0, t}$ is also a monotonically increasing, convex relationship in which

$$
\lim _{x_{0, t} \rightarrow \infty} x_{1, t+1}=\left(\frac{1-b_{m}}{b_{m}}\right) x_{1, \max }
$$

which I will denote by $K$. However, Equations 5 and 6 have unusual mathematical properties that limit their applicability to general biological situations. Only when $b_{m}=1 / 2$ does $\lim _{x_{0, t} \rightarrow \infty} x_{1, t+1}=x_{1, \max }$, and $b_{m}$ is the baseline mortality only if $x_{0, t}=x_{1, \max }$. 
Multiplying the numerator and denominator of $S_{1}$ by $1 /\left(1-b_{m}\right)$ yields

$$
S_{1}\left(x_{0, t}\right)=\frac{1}{1+\frac{b_{m}}{\left(1-b_{m}\right) x_{1, \max }} x_{0, t}}=\frac{1}{1+\frac{x_{0, t}}{K}} .
$$

Thus, the density-dependent survival function used by Spromberg and Meador (2005, 2006) is a one-parameter model that is equivalent to my survival model (Equation 4) if and only if $S_{b}=1$. I include a second parameter $S_{b} \leq 1$ under the assumption that survival is not necessarily one even under density-independent conditions.

I can now describe the population with the matrix model

$$
\left[\begin{array}{c}
x_{0} \\
x_{1} \\
x_{2} \\
x_{3} \\
\vdots \\
x_{n}
\end{array}\right]_{t+1}=\left[\begin{array}{cccccc}
0 & 0 & \beta_{2} & \beta_{3} & \ldots & \beta_{n} \\
S_{1}\left(x_{0, t}\right) & 0 & 0 & 0 & \ldots & 0 \\
0 & S_{2} & 0 & 0 & \ldots & 0 \\
0 & 0 & S_{3} & 0 & \ldots & 0 \\
\vdots & \vdots & \vdots & \ddots & & \vdots \\
0 & 0 & \ldots & 0 & S_{n} & 0
\end{array}\right]\left[\begin{array}{c}
x_{0} \\
x_{1} \\
x_{2} \\
x_{3} \\
\vdots \\
x_{n}
\end{array}\right]_{t}
$$

where $\beta_{j}$ account for the mean number of female fry produced by one mature female in age class $j$ and age 2 is the youngest age that an individual can become reproductively mature. Without loss or gain, I can analogously depict the system in 8 as

$$
\begin{aligned}
x_{0, t+1} & =\sum_{j=2}^{n} \beta_{j} x_{j, t} \\
x_{1, t+1} & =S_{1}\left(x_{0, t}\right) x_{0, t} \\
x_{j, t+1} & =S_{j} x_{j-1, t}, \text { for } j=2: n .
\end{aligned}
$$


Substituting Equation 9c into 9a and 9b yields

$$
\begin{aligned}
& x_{0, t+1}=\sum_{j=2}^{n} \beta_{j}\left(\prod_{k=2}^{j} S_{k}\right) \cdot x_{1, t-j+1} \\
& x_{1, t+1}=S_{1}\left(x_{0, t}\right)\left[\sum_{j=2}^{n} \beta_{j}\left(\prod_{k=2}^{j} S_{k}\right) \cdot x_{1, t-j}\right],
\end{aligned}
$$

i.e., with nonlinearity only in survival from $x_{0}$ to $x_{1}$, the system collapses into two equations in $x_{0}$ and $x_{1}$.

At equilibrium, $x_{j, t+1}=x_{j, t}=x_{j}^{*}$, and substituting this into Equation 10 gives the equilibrium equations

$$
\begin{aligned}
x_{0}^{*} & =x_{1}^{*}\left[\sum_{j=2}^{n} \beta_{j}\left(\prod_{k=2}^{j} S_{k}\right)\right] \\
x_{1}^{*} & =S_{1}\left(x_{0}^{*}\right) x_{1}^{*}\left[\sum_{j=2}^{n} \beta_{j}\left(\prod_{k=2}^{j} S_{k}\right)\right] \\
& =\frac{S_{b}}{1+\alpha x_{0}^{*}} x_{1}^{*}\left[\sum_{j=2}^{n} \beta_{j}\left(\prod_{k=2}^{j} S_{k}\right)\right],
\end{aligned}
$$

where I used Equation 4. Let $R=\sum_{j=2}^{n} \beta_{j}\left(\prod_{k=2}^{j} S_{k}\right)$, which represents the expected number of female fry $\left(x_{0}\right)$ produced over the lifetime of a female recruit $\left(x_{1}\right)$, hereafter referred to as reproductive potential of a population. The system in 11 has a trivial solution $x_{0}^{*}=x_{1}^{*}=x_{j}^{*}=0$ and a nontrivial solution that solves

$$
\begin{aligned}
x_{0}^{*} & =R x_{1}^{*} \\
1 & =\frac{R S_{b}}{1+\alpha x_{0}^{*}},
\end{aligned}
$$


which leads to the equilibrium solutions

$$
\begin{aligned}
x_{0}^{*} & =\frac{R S_{b}-1}{\alpha} \text { and } \\
x_{1}^{*} & =\frac{R S_{b}-1}{R \alpha},
\end{aligned}
$$

where $R S_{b}$ is the expected number of female recruits into age 1 produced over the lifetime of a female recruit under low densities, hereafter referred to as the recruitment potential. Persistence of the population requires

$$
R S_{b}>1
$$

Emergent fry are typically not included in population estimates and will not be counted into the equilibrium size of this system. The non-trivial equilibrium population size, $E$ is then

$$
\begin{aligned}
E & =\sum_{j=1}^{n} x_{j}^{*} \\
& =\frac{R S_{b}-1}{R \alpha}\left(1+S_{2}+S_{2} S_{3}+\ldots+S_{2} S_{3} \cdots S_{n-1} S_{n}\right),
\end{aligned}
$$

if $S_{2}=S_{3}=\ldots=S_{n-1}=S_{n}=S$, then

$$
1+S_{2}+S_{2} S_{3}+\ldots+S_{2} S_{3} \cdots S_{n-1} S_{n}=\frac{1-S^{n+1}}{1-S}
$$

Non-dimensionalization by the Equilibrium Population Size

Non-dimensionalization of the system 9 or 8 by $E$ will scale out the carrying capacity parameter $\alpha$. Doing so will simplify the analysis and make the system applicable to any pop- 
ulation by forcing the non-trivial equilibrium population size to be one, thereby expressing effects of toxicity on the population as fractional reductions in the inherent environmental carrying capacity as was illustrated for the logistic growth model on page 12 . Let the dimensionless variables $\tilde{x}_{j}$ be denoted as

$$
\begin{aligned}
\tilde{x}_{j, t+1} & =\frac{R \alpha}{\left(R S_{b}-1\right)\left(1+S_{2}+S_{2} S_{3}+\ldots+S_{2} S_{3} \cdots S_{n-1} S_{n}\right)} \cdot x_{j, t+1} \text {. Thus } \\
x_{j, t+1} & =\frac{\left(R S_{b}-1\right)}{R \alpha}\left(1+S_{2}+S_{2} S_{3}+\ldots+S_{2} S_{3} \cdots S_{n-1} S_{n}\right) \cdot \tilde{x}_{j, t+1} \text { for } j=1: n .
\end{aligned}
$$

Substituting the $x_{j, t+1}$ above into the system in 9 and solving for the unitless variables simplifies the non-dimensional system to

$$
\begin{aligned}
\tilde{x}_{0, t+1} & =\sum_{j=2}^{n} \beta_{j} \tilde{x}_{j, t} \\
\tilde{x}_{1, t+1} & =\frac{S_{b}}{1+\frac{R S_{b}-1}{R}\left(1+S_{2}+S_{2} S_{3}+\ldots+S_{2} S_{3} \cdots S_{n-1} S_{n}\right) \tilde{x}_{0, t}} \tilde{x}_{0, t} \\
\tilde{x}_{j, t+1} & =S_{j} \tilde{x}_{j-1, t} \text { for } j=2: n .
\end{aligned}
$$

The equilibria of the non-dimensional system satisfy $\tilde{x}_{j, t+1}=\tilde{x}_{j, t}=\tilde{x}_{j}^{*}$, which obviously has the trivial solution $x_{j}^{*}=0$. The non-trivial equilibria solution is

$$
\begin{gathered}
\tilde{x}_{0}^{*}=\frac{R}{1+S_{2}+S_{2} S_{3}+\ldots+S_{2} S_{3} \cdots S_{n-1} S_{n}} \\
\tilde{x}_{1}^{*}=\frac{1}{1+S_{2}+S_{2} S_{3}+\ldots+S_{2} S_{3} \cdots S_{n-1} S_{n}} \\
\tilde{x}_{j}^{*}=S_{j} \tilde{x}_{j-1}^{*} \text { for } j=2: n .
\end{gathered}
$$


Thus, the equilibrium population size of the dimensionless system, not counting fry, is

$$
\tilde{E}=\sum_{j=1}^{n} \tilde{x}_{j}^{*}=1
$$

as desired.

Incorporating Mortality due to Toxicity

I incorporate toxin-dependent mortality into the susceptible juvenile age class. As in Haddon (2001), I define instantaneous total mortality per year at low densities as $Z=$ $M+t o x$ where tox is the mortality due to toxicity and $M$ incorporates natural, fishing, and other sources of mortality. That is, the survival rate over one year is $e^{-Z}=e^{-M} e^{-t o x}$ where $e^{-M}=S_{b}$. Let $M_{t o x}(C)$ be the additional annual mortality imposed due to toxin exposure as a function of toxin concentration $C$, i.e. $M_{t o x}=1-e^{-t o x}$. For notational convenience I define $S_{t o x}(C)=1-M_{t o x}(C)$ and use $S_{t o x}(C)$ for most derivations. Then, overall annual survival at low densities is $S_{b} S_{t o x}$ and density-dependent survival is $S_{1}\left(S_{t o x}(C) \cdot \tilde{x}_{0, t}\right) S_{t o x}(C)$, so that the number of age 1 fish is given by

$$
\tilde{x}_{1, t+1}=\frac{S_{b} \cdot S_{t o x}(C) \cdot \tilde{x}_{0, t}}{1+\frac{R S_{b}-1}{R}\left(1+S_{2}+S_{2} S_{3}+\ldots+S_{2} S_{3} \cdots S_{n-1} S_{n}\right) S_{t o x}(C) \tilde{x}_{0, t}} .
$$

To investigate effects of this additional mortality on persistence, I will perform a linear equilibrium analysis of the system in 8 that now includes toxin-dependent survival on the juvenile class. The Jacobian of 8 evaluated at $(0,0, \ldots, 0)$ is 


$$
\left.J\right|_{(0, \ldots, 0)}=\left[\begin{array}{cccccc}
0 & 0 & \beta_{2} & \beta_{3} & \ldots & \beta_{n} \\
S_{b} S_{t o x}(C) & 0 & 0 & 0 & \ldots & 0 \\
0 & S_{2} & 0 & 0 & \ldots & 0 \\
0 & 0 & S_{3} & 0 & \ldots & 0 \\
\vdots & \vdots & \vdots & \ddots & & \vdots \\
0 & 0 & \ldots & 0 & S_{n} & 0
\end{array}\right]
$$

Solving $\left.J\right|_{(0, \ldots, 0)} \vec{x}=\lambda \vec{x}$ by back-substitution gives us an $(n+1)^{t h}$ order equation in $\lambda$. We would like to find a curve that depicts the boundary between population persistence and extinction, that is when $\lambda=1$. This leads to the equilibrium equation

$$
\frac{1}{S_{b} S_{t o x}(C)}=\sum_{j=2}^{n} \beta_{j}\left(\prod_{k=2}^{j} S_{k}\right)=R
$$

Persistence of the population requires that $R S_{b} S_{t o x}(C)>1$, which reduces to $R S_{b}>1$ when $S_{t o x}(C)=1$ as shown in the inequality in 12 .

Replacement of Equation 13a with Equation 16 and summing over all age classes except the fry class yields

$$
\tilde{E}(C)=\sum_{j=1}^{n} \tilde{x}_{j}=\frac{R S_{b} S_{t o x}(C)-1}{\left(R S_{b}-1\right) S_{t o x}(C)}
$$

where $\tilde{E}(C)$ is the dimensionless equilibrium population size under the effect of toxicity. $\tilde{E}(C)$ is maximally impacted, that is $\tilde{E}(C)=0$, when $S_{t o x}(C)=1 /\left(R S_{b}\right), \tilde{E}(C)$ is increasing with $S_{t o x}(C)$ when $1 /\left(R S_{b}\right)<S_{t o x}(C) \leq 1$, and $\tilde{E}(C)=1$ when $S_{t o x}(C)=1$.

To establish a relationship between population-level and individual-level toxicity effects, let $P(C)=1-\tilde{E}(C)$ be the fractional decline from carrying capacity and let the individual-effect be $M_{t o x}(C)=1-S_{t o x}(C)$, which is the toxin-induced mortality of indi- 
viduals. Then Equation 19 yields

$$
P(C)=\frac{M_{t o x}}{\left(R S_{b}-1\right)\left(1-M_{t o x}\right)} .
$$

The population-level effect is less than the individual-level effect when $P<M$, i.e. when $M_{t o x}<\left(R S_{b}-2\right) /\left(R S_{b}-1\right)$. I require $M_{t o x}<\left(R S_{b}-1\right) /\left(R S_{b}\right)$ for population persistence, (Figure 1), so the population-level effect is greater than the individual-level effect when

$$
\frac{R S_{b}-2}{R S_{b}-1}<M_{t o x}<\frac{R S_{b}-1}{R S_{b}}
$$

Notice for large $R S_{b}$, that is, for very large recruitment potential (i.e., $R S_{b} \rightarrow \infty$ ), that

$$
\lim _{R S_{b} \rightarrow \infty} P(C)= \begin{cases}0, & 0 \leq M_{t o x}<1 \\ 1, & \text { as } M_{t o x} \rightarrow 1^{-}\end{cases}
$$

Now I will establish a function to describe additional juvenile mortality due to toxin exposure.

Specific form of the Toxin-Dependent Survival Function $S_{t o x}(C)$

In general, I want a sigmoidal response of a life history parameter to toxin concentration (Spromberg and Meador, 2005, 2006; Van Kirk and Hill, 2007; McIntyre et al., 2008). Typically, toxicity affects fish demography by decreasing juvenile survival $S_{1}\left(x_{0, t}\right)$. Data from an experimental setting can be used to determine the decreased survival that a toxin imposes on freshwater fish. Survival values must first be modified to eliminate background mortality levels experienced by all subjects in the experimental treatment to identify the 


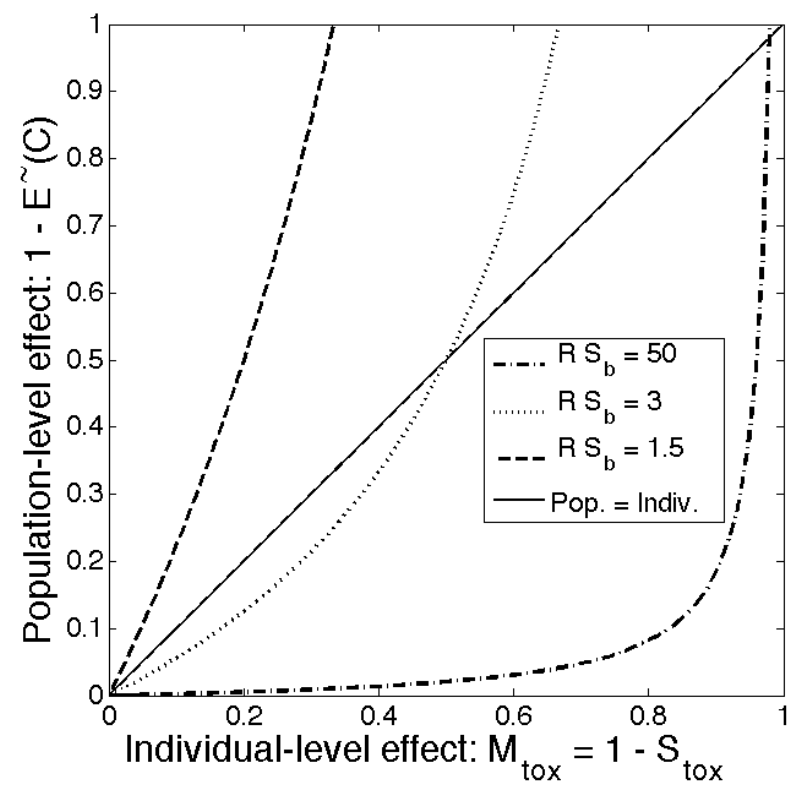

Figure 1: Population-level versus individual-level toxicity effect for several values of recruitment potential $R S_{b}$. The solid line is the identity line, at which population-level effect and individual-level effect are equal.

treatment effect of the toxin. Mortality due solely to toxin exposure is defined as

$$
M_{t o x}=1-\frac{S_{t o t a l}}{S_{c}}
$$

where $S_{\text {total }}$ is survival rate of fish at a specified treatment level, and $S_{c}$ is the survival rate of the control fish in the same experiment (Van Kirk and Hill, 2007).

Many types of sigmoidal models are available, but I chose variations on the logistic curve because of its well-known statistical properties and interpretation in terms of odds (Ramsey and Schafer, 2002). Two candidate models were considered, the standard logistic function given by

$$
S_{t o x 1}(C)=\frac{1}{1+\exp (-a+b C+\epsilon)}, b>0
$$


and the log-logistic function

$$
\begin{aligned}
S_{\text {tox } 2}(C) & =\frac{1}{1+\exp (-a+b \ln (C)+\epsilon)}, b>0 \\
& =\frac{1}{1+\exp (-(a+\epsilon)) C^{b}}
\end{aligned}
$$

$S_{t o x 1}(C)$ and $S_{t o x 2}(C)$ are the survival rates at a given whole-body toxin concentration $C, b$ is a slope parameter, and $\epsilon$ is a normally distributed random variable with mean zero and variance $\sigma^{2}$. A more desirable model is $\operatorname{logit}\left(S_{t o x 1}\right)=a-b C$ or $\operatorname{logit}\left(S_{t o x 2}\right)=$ $a-b \ln (C)$, with $S_{t o x 1}$ or $S_{t o x 2}$ having a binomial distribution, but the binary response data to perform logistic regression is not typically available from experimental trials in the published literature. However, $\operatorname{logit}\left(S_{t o x}\right)$ has a normal sampling distribution as $n \rightarrow \infty$ (Ramsey and Schafer, 2002), and the logit of $S_{t o x 1}$ and $S_{t o x 2}$ links the response $S_{t o x 1}$ and $S_{t o x 2}$ of Equations 23 and 24 to the linear models given by

$$
\begin{gathered}
\ln \left(\frac{S_{t o x 1}}{1-S_{t o x 1}}\right)=a-b C+\epsilon \\
\ln \left(\frac{S_{t o x 2}}{1-S_{t o x 2}}\right)=a-b \ln (C)+\epsilon .
\end{gathered}
$$

I expected $S_{t o x 2}$ to be a better model because of its property that $S_{t o x 2}(C=0)=1$, the fact that $C$ is generally lognormally distributed, and its use by others (Cedergreen et al., 2005; Lopes et al., 2005; Mebane and Arthaud, 2010). Indeed, I found it to be a better fit (i.e. higher likelihood) to bluegill-selenium data (see next section).

For mean toxicity response given by Equation 24, the dimensionless equilibrium popu- 
lation size from Equation 19 can be redefined as

$$
\tilde{E}(C)=1-\left(\frac{C}{L C_{50}}\right)^{b} \cdot \frac{1}{R S_{b}-1}
$$

where $L C_{50}=e^{a / b}$ is the toxin concentration at which the mean mortality is $50 \%, b>0$ is the opposite of the slope in the logit $\left(S_{\text {tox }}\right)$ vs. $\ln (C)$ line in Equation 26, and $e^{b}$ is the multiplicative increase in odds of mortality per unit increase in $\ln (C)$ (Neter et al., 1989; Ramsey and Schafer, 2002). Equation 27 explicitly identifies the relationship between the equilibrium size of a population and the four important parameters $L C_{50}, b, R$ and $S_{b}$.

From Equation 19, persistence occurs when

$$
R S_{b} S_{t o x}>1
$$

Substituting the selenium-dependent survival function from Equation 24 into the inequality in 28 results a direct relationship amongst the four parameters $L C_{50}, R, S_{b}$, and $b$. Thus, persistence requires

$$
C<L C_{50}\left(R S_{b}-1\right)^{1 / b},
$$

with $b>0$. Equation 27 suggests an intuitive dimensionless variable $\tilde{C}$

$$
\tilde{C}=\frac{C}{L C_{50}}
$$

Solving Equation 30 for $C$ and substituting into Equation 27 reduces Equation 27 to a dimensionless equilibrium population size as a function of a dimensionless toxin concen- 


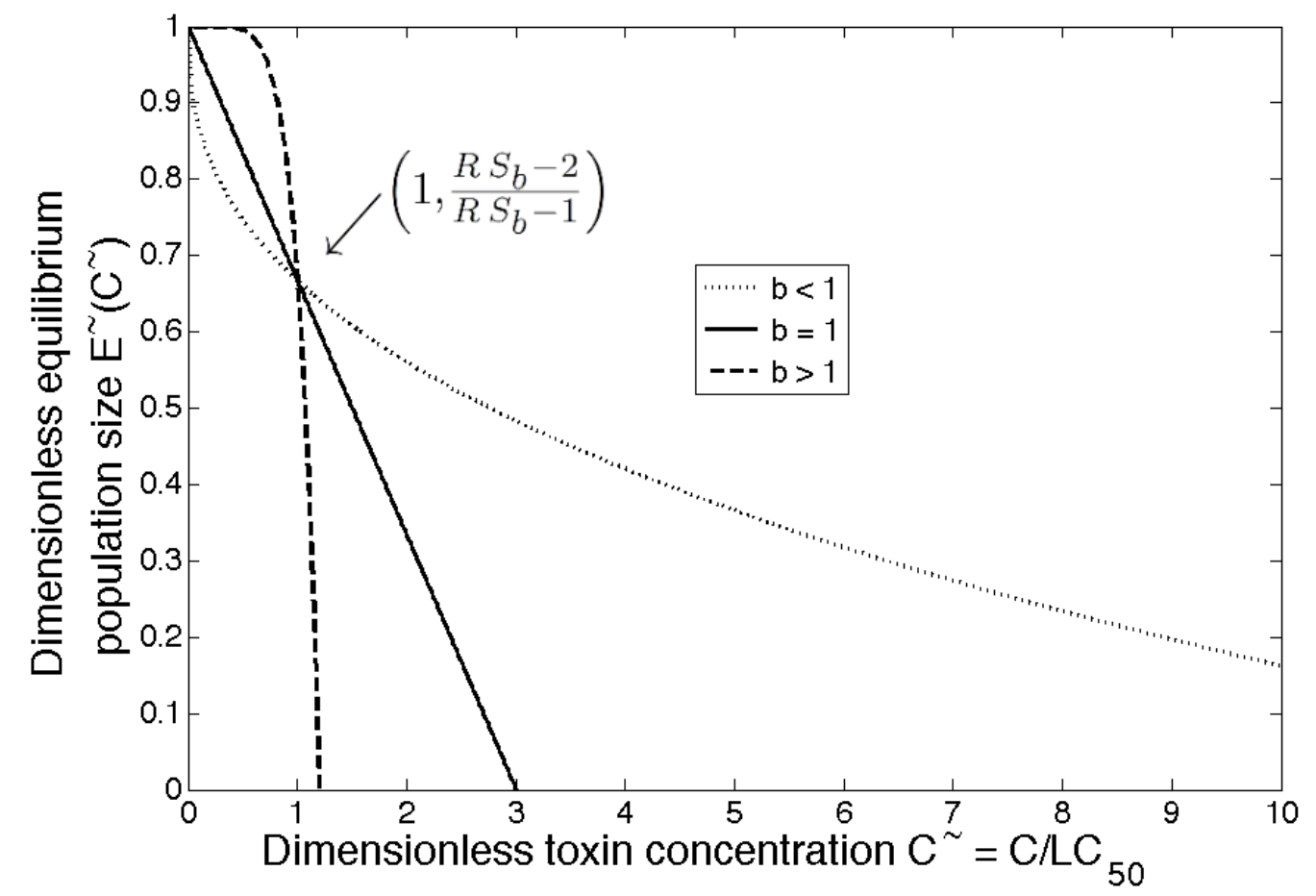

Figure 2: Dimensionless equilibrium population size as a function of dimensionless toxin concentration, $\tilde{E}(\tilde{C})=1-\tilde{C}^{b} /\left(R S_{b}-1\right)$, for several values of $b$ with fixed $R S_{b}=4$.

tration:

$$
\tilde{E}(\tilde{C})=1-\frac{\tilde{C}^{b}}{R S_{b}-1}, b>0 .
$$

Figure 2 shows the graph of Equation 31 for several values of the slope parameter $b$ with fixed $R S_{b}=4$. Notice for any $b$, when the individual level effect is $50 \%$ (that is, when $\tilde{C}=1$ or equivalently when $\left.C=L C_{50}\right), \tilde{E}(\tilde{C})=\left(R S_{b}-2\right) /\left(R S_{b}-1\right)$.

I will now implement this framework to investigate impacts of selenium toxicity to bluegill sunfish using the log-logistic toxin survival function in Equation 24. 


\section{Deterministic Population Model for Bluegill Sunfish}

To proceed further, I need specific values for $R, L C_{50}$, and $b$, and because $S_{b}$ is typically unknown, I will treat it as a parameter. I chose seven years as the maximum attainable age for bluegill sunfish, as older individuals are quite rare (Belk, 1995). The reproductive contribution of an individual in age class $j$ is

$$
\beta_{j}=\frac{1}{2} \cdot P(j) \cdot F(L(j)) \cdot S_{e f},
$$

where $L(j)$ is the mean length at age $j, F(L)$ is the length-specific fecundity, $P(j)$ is the age-specific maturation probability, and $S_{e f}$ is the egg-to-fry survival rate. Melbourne and Hastings (2008) showed that demographic heterogeneity can affect population dynamics and extinction probability, but I assumed of a 1:1 sex ratio as is standard in classical demographic modeling. For bluegill sunfish, $L(j)$ follows a von Bertalanffy growth model. Parameters were estimated using maximum likelihood using different error structures, see Table 1 (Neter et al., 1989; Haddon, 2001). Neither additive error model produced normally distributed residuals, even though the weighted model satisfied homoskedasticity requirements better than the unweighted model. The lognormal model had the best error properties. Figure 3 shows the different fits.

Data allowing statistical analysis of bluegill mortality as a function of whole-body selenium concentration were compiled for the indicated trial durations in three peer-reviewed studies: Lasting 60 and 90 days (Cleveland et al., 1993), 180 days (Lemly, 1993b), and 171 and 177 days (McIntyre et al., 2008). All references to selenium concentrations are expressed in dry weight. Bluegill were exposed to cold $(n=3)$ and warm $(n=10)$ water temperatures. The cold water exposures were intended to mimic the onset of winter conditions, which were maintained at $4^{\circ} \mathrm{C}$ or $9^{\circ} \mathrm{C}$ (see Lemly, 1993b; McIntyre et al., 2008). 
Table 1: Fitting the von Bertalanffy growth model with different error structures.

Error type Model

Error distribution

\begin{tabular}{lll}
\hline \hline Additive Normal error & $L(j)=L_{\infty}\left(1-e^{-k\left(j-t_{0}\right)}\right)+\epsilon$ & $\epsilon \sim N\left(0, \sigma^{2}\right)$ \\
Weighted Additive Normal error & $L(j)=L_{\infty}\left(1-e^{-k\left(j-t_{0}\right)}\right)+\epsilon$ & $\epsilon \sim N\left(0, \sigma_{i}^{2}\right)$, \\
& & $\sigma_{i}^{2}=\sigma^{2} L_{i}^{2}$ \\
Multiplicative lognormal error & $L(j)=L_{\infty}\left(1-e^{-k\left(j-t_{0}\right)}\right) e^{\epsilon}$ & $\epsilon \sim N\left(0, \sigma^{2}\right)$ \\
& & \\
\hline
\end{tabular}

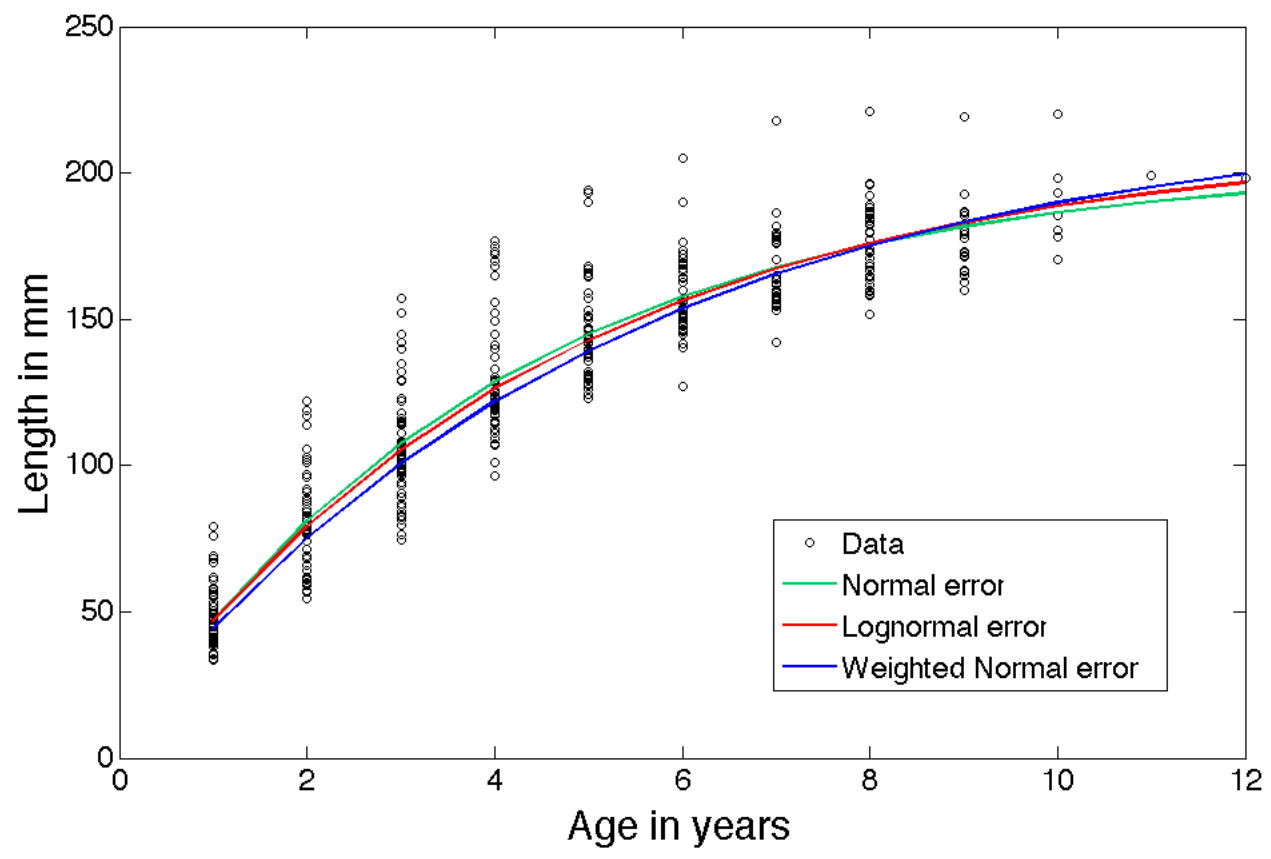

Figure 3: Comparison of the fitted curves for the von Bertalanffy growth model. 
Table 2: Model parameters and variables for bluegill sunfish.

Parameter Parameter Estimate Reference(s)

\begin{tabular}{|c|c|c|}
\hline Egg-to-fry survival rate & $S_{e f}=0.88$ & Henry and Grizzle (2004) \\
\hline $\begin{array}{l}\text { Density-dependent fry- } \\
\text { to-age } 1 \text { survival rate }\end{array}$ & Equation 4 & Henle et al. (2004) \\
\hline $\begin{array}{l}\text { Age 1-to-age } 2 \\
\text { survival rate }\end{array}$ & $S_{2}=0.33$ & Belk and Hales Jr. (1993) \\
\hline Adult survival rate & $S=0.3377$ & $\begin{array}{l}\text { Gillen et al. (1981), } \\
\text { Belk and Hales Jr. (1993), } \\
\text { Parsons and Reed (1998), } \\
\text { Paukert et al. (2001), } \\
\text { Crawford and Allen (2006), } \\
\text { Sammons et al. (2006), } \\
\text { Sammons and Maceina (2009) }\end{array}$ \\
\hline Reproductive potential & $R=304.4116$ & \\
\hline Maximum life span & $n=7$ years & Belk (1995) \\
\hline $\begin{array}{l}\text { Selenium-dependent } \\
\text { survival rate }\end{array}$ & Equation 24 & See Figure 4 \\
\hline $\begin{array}{l}\text { Fecundity } \\
\text { (eggs/spawner) }\end{array}$ & $F=0.0046(L)^{2.839}$ & Panek and Cofield (1978) \\
\hline Age-2 maturity rate & 0.6130 & Tomcko and Pereira (2006) \\
\hline Age- 3 maturity rate & 0.7638 & \\
\hline Age-4 maturity rate & 0.8429 & \\
\hline Age-5 maturity rate & 0.8882 & \\
\hline Age-6 maturity rate & 0.9163 & \\
\hline Age-7 maturity rate & 0.9349 & \\
\hline $\begin{array}{l}\text { Von Bertalanffy growth } \\
\text { model maximum } \\
\text { likelihood estimates } \\
\text { with multiplicative } \\
\text { lognormal error }\end{array}$ & $\begin{array}{l}L_{\infty}=211.6618 \\
k=0.2189 \\
t_{0}=-0.1435 \\
\hat{\sigma}^{2}=0.0222\end{array}$ & $\begin{array}{l}\text { See Figure 3, } \\
\text { Gerking (1962), } \\
\text { Belk and Hales Jr. (1993), } \\
\text { Schneider and Lockwood (1997), } \\
\text { Schneider et al. (2000), } \\
\text { Paukert et al. (2001) } \\
\text { Tomcko and Pereira (2006) }\end{array}$ \\
\hline
\end{tabular}


Table 3: Maximum Likelihood Results for the Selenium-Dependent Survival Functions.

\begin{tabular}{clc} 
Survival Function Type & Parameter Estimates & Deviance \\
\hline \hline Logistic function & $a=-3.4506$ & 48.2532 \\
$S_{s e 1}$ & $b=0.2980$ & \\
& $\hat{\sigma}^{2}=2.3962$ & \\
Log-logistic function & $a=5.3589$ & 46.6784 \\
$S_{s e 2}$ & $b=2.2434$ & \\
& $\hat{\sigma}^{2}=2.1229$ & \\
\hline
\end{tabular}

The temperature in the warm water exposures were maintained at $20^{\circ} \mathrm{C}$ (Lemly, 1993b) and at $25^{\circ} \mathrm{C}$ (Cleveland et al., 1993). Although the exposure durations and water temperature regimes varied across studies, I interpret the range of experimental conditions across studies as a reflection of environmental variability in toxicity effects. Thus, fitting a single toxicity curve to data pooled across these studies captures this variability.

Parameter estimates for $a, b$ and $\sigma^{2}$ were obtained using maximum likelihood methods applied to Equations 23 and 24. Under the assumption that the observed survival response was random at fixed concentration values, the residual deviance indicated that the loglogistic function was a better fit to the data (see Table 3 and Figure 4). For use in the stochastic model (next section), I adjusted the maximum likelihood estimate (MLE) of variance $\left(\hat{\sigma}_{M L E}^{2}\right)$ for bias and replaced it with its least-squares estimate $\left(\hat{\sigma}^{2}\right)$. That is, $\hat{\sigma}^{2}=n /(n-2) \hat{\sigma}_{M L E}^{2}$, where $n$ is the number of data points.

On average, $R \approx 304.4116$ for bluegill sunfish, and selenium concentrations of $C>$ 139.2584 will result in extinction when $S_{b}=1$. This large value of $C$ is due to the high fecundities of bluegill resulting in large $R$. In practice though, $S_{b}$ is likely to be less than one. Given the selenium-dependent survival for juvenile bluegill described in Equation 24, 


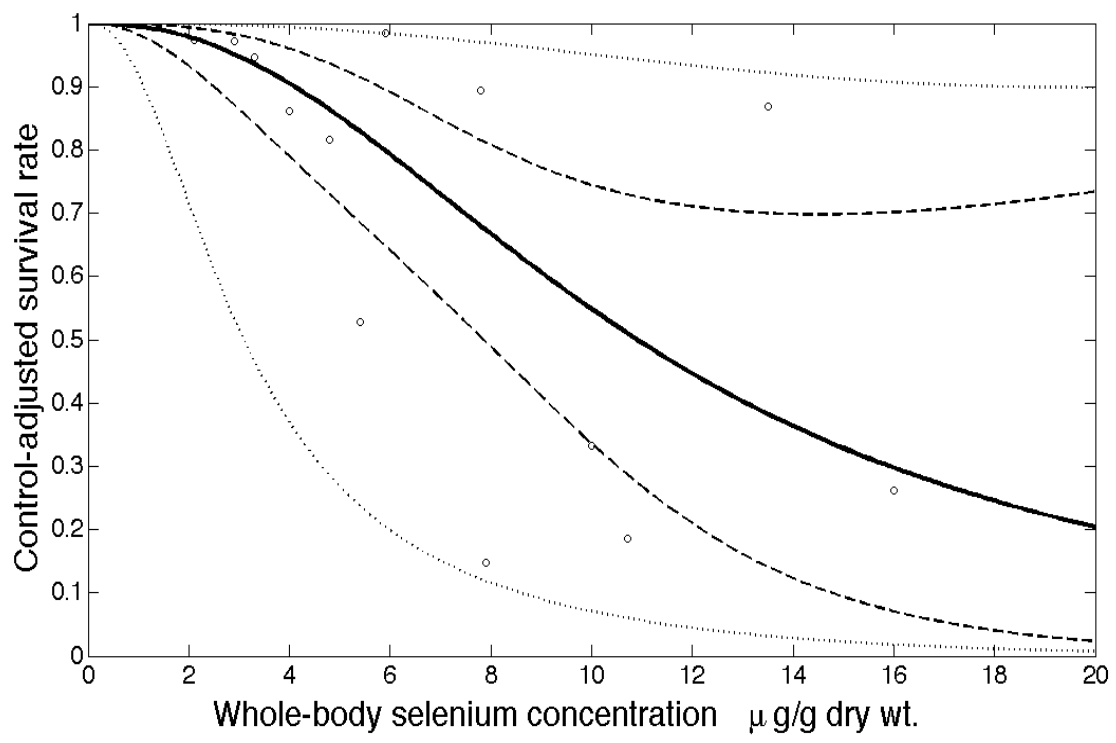

Figure 4: Control-adjusted survival versus whole body selenium concentration. The circles represent data from peer-reviewed studies, the thick curve is the mean survival response in Equation 24, the dashed curves bound the $95 \%$ confidence intervals, and the dotted curves bound the $95 \%$ predication intervals.

Figure 5 shows a graph of $S_{b}=1 /\left(R S_{s e}(C)\right)$ for variable first-year baseline survival rates $S_{b}$ corresponding to when the PGR $\lambda=1$, as established in Equation 29. Clearly, additional mortality due to toxicity will decrease the PGR of a population, but the equilibrium size also responds to increased mortality. As established in the previous section, the non-trivial equilibrium size of a population is a decreasing function of toxin concentration, which is not apparent had the PGR been used as the only population-level endpoint.

Bifurcation analysis can describe the relationship between the effects of additional mortality due to toxicity on the PGR and those on equilibrium population size $\tilde{E}$, in which the equilibrium size is considered as a function of the bifurcation parameter $C$, the toxin concentration (Figure 6). The equilibrium size is the sum of the components of the nontrivial solution to the system in Equations 14 - 15. When this sum is positive, it represents the stable equilibrium to the dynamic system in Equations 13, in which the PGR $>1$, 


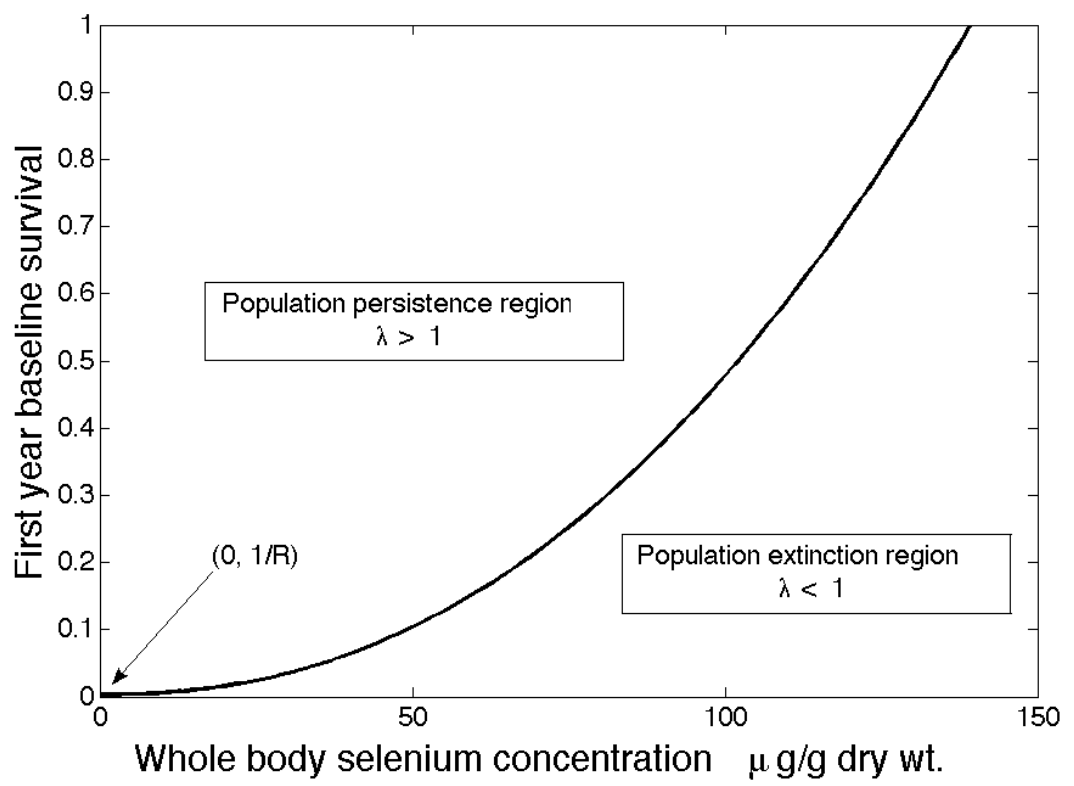

Figure 5: Persistence and extinction regions corresponding to when $\lambda=1$ and $\tilde{E}(C)=0$, that is $S_{b}=1 /\left(R S_{s e}(C)\right)$. $S_{b}$ as a function of whole-body selenium concentration for $R=304.4116$.

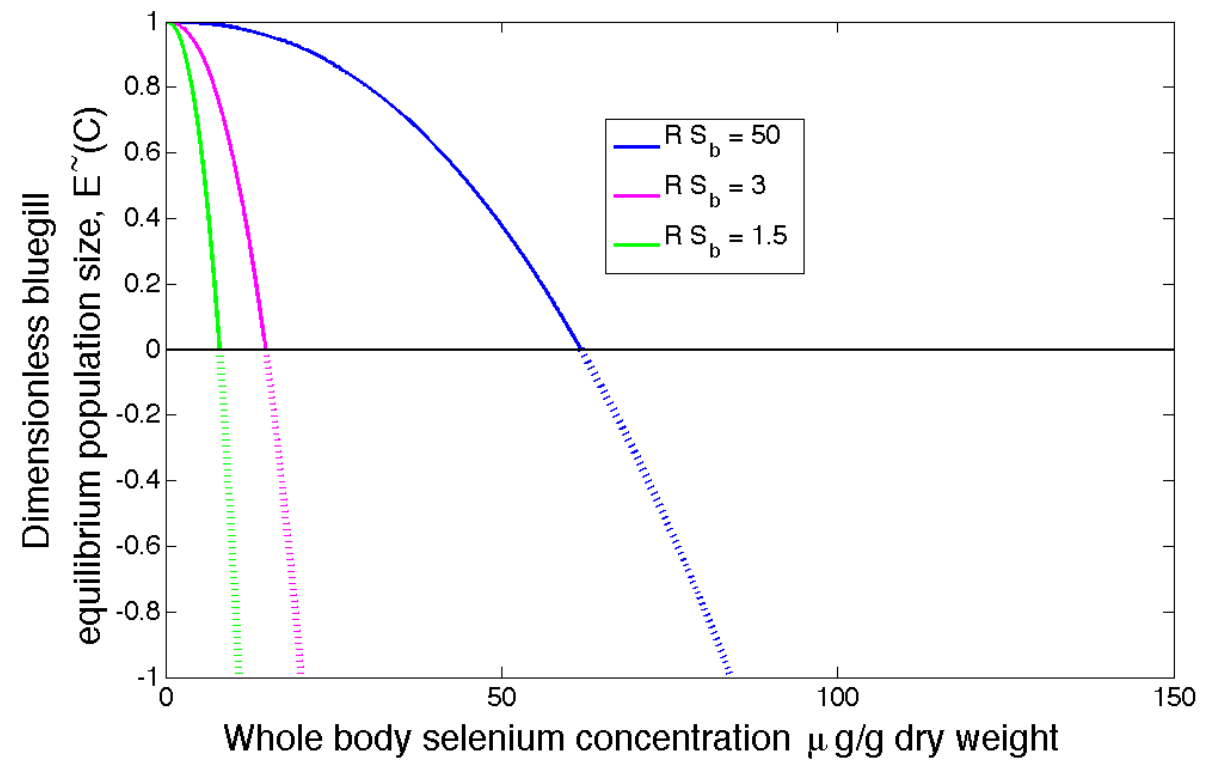

Figure 6: Bifurcation diagram depicting the stability change of $\tilde{E}(C)$ for several values of $R S_{b}$ Equation 19. The bold curves indicate that the positive nontrivial equilibrium is stable, and the dashed curves indicate that the nontrivial equilibrium becomes unstable. 
$R S_{b} S_{t o x}>1$, the population persists, and the trivial equilibrium is unstable. The equilibrium size decreases as toxin concentration $C$ increases (Figure 6). When the equilibrium size is zero $(\tilde{E}=0)$, the nontrivial solution to Equations 14 - 15 and the trivial solution are both zero, and neither solution is stable. This bifurcation point

$$
C=L C_{50}\left(R S_{b}-1\right)^{1 / b}
$$

corresponds to the location at which the PGR $=1$, that is, $R S_{b} S_{\text {tox }}=1$. When toxin concentrations exceed this bifurcation point, the PGR $<1, R S_{b} S_{t o x}<1$, and the trivial equilibrium becomes stable, corresponding to population extinction. A nontrivial solution to Equations 14 - 15 exists at concentrations exceeding the bifurcation point, but it has no biological significance because it is negative. This solution is the unstable equilibrium to the dynamic system in Equations 13. This exchange of stability is called a transcritical bifurcation (Strogatz, 1994) and is the same type of bifurcation that the simple logistic model (Equation 3) exhibits when additional mortality exceeds the intrinsic PGR, that is when $\alpha>r$. Considering the PGR as the sole population-level endpoint is equivalent to using Figure 6 only to identify the bifurcation points, that is the points at which $\tilde{E}=0$. These points are identified through the linear analysis of the linear system in Equation 17. As the toxin concentration is increased, both the PGR and equilibrium size are decreased (Figures 5 and 6). But the decrease in population size is apparent only when I consider the full nonlinear system in Equation 13. The impacts on the equilibrium size would have been overlooked had I only considered the linear analysis of the system in Equation 17.

A three-dimensional plot for the persistence/extinction boundary $(\lambda=1)$ of the dimensionless equilibrium population size as a function of both selenium concentration and baseline first-year survival $\tilde{E}\left(S_{b}, C\right)$ for fixed $R=304.4116$ is in Figure 7. The intersec- 


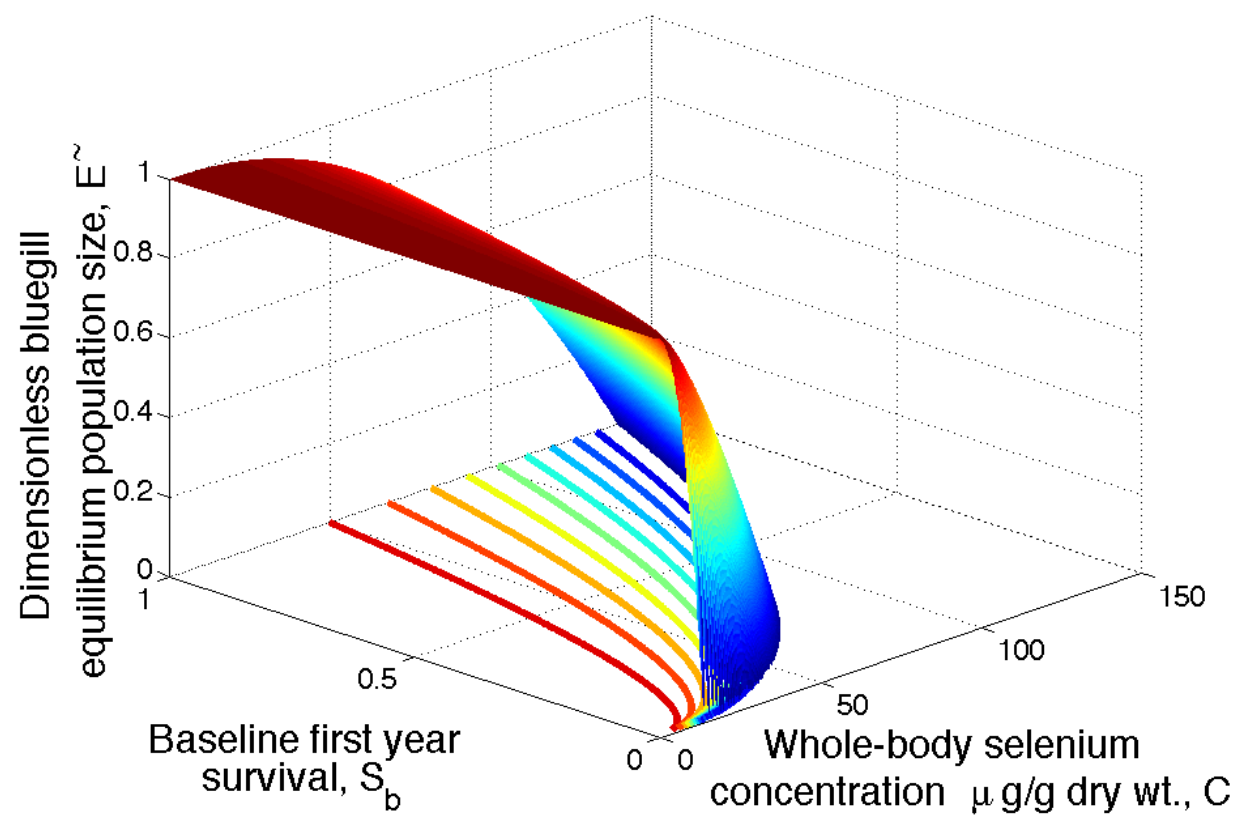

Figure 7: Bluegill persistence and extinction regions of the dimensionless equilibrium population size, $\tilde{E}$ as a function of selenium concentration and $S_{b}$. $R$ is fixed at $R=304.4116$.

tion of the surface in Figure 7 and the $C-S_{b}$ plane depicts where $\tilde{E}=0$ analogous to the graph of the persistence region for the trivial equilibrium in Figure 5.

Stochastic Population Model for Bluegill Sunfish

Environmental variability was incorporated into the bluegill population model, but demographic stochasticity was not. Stochasticity was incorporated into all growth and survival rates to describe background levels of environmental variability.

\section{$\underline{\text { Stochastic Growth }}$}

The stochastic annual growth in length of a cohort was modeled as the growth ratio in length between two ages from the von Bertalannfy model with a stochastic component. 
Let the mean length of a cohort of age $j$ be $\mu_{j}=L_{\infty}\left(1-\exp \left(-k\left(j-t_{0}\right)\right)\right)$ where all parameters in $\mu_{j}$ and $\sigma^{2}$ were estimated as described previously (Table 2), that is, the fitted model was $\ln \left(L_{j}\right)=\ln \left(\mu_{j}\right)+Y$ with $Y \sim N\left(0, \sigma^{2}\right)$. Then the log-increment in growth is $\ln \left(L_{j}\right)-\ln \left(L_{j-1}\right)=\ln \left(\mu_{j}\right)-\ln \left(\mu_{j-1}\right)+Z$ with $Z \sim N\left(0,2 \sigma^{2}\right)$, by properties of linear combinations of random variables. I randomly selected $L_{1}$ from a normal distribution with mean $\mu_{1}$ and variance $\sigma^{2}$. Then for $j=2, \ldots, 7$, I calculated a random length of the cohort the next year as $\ln \left(L_{j}\right)=\ln \left(L_{j-1}\right)+\ln \left(\mu_{j}\right)-\ln \left(\mu_{j-1}\right)+Z$, or $L_{j}=L_{j-1}\left(\frac{\mu_{j}}{\mu_{j-1}}\right) e^{Z}$, where I randomly select $Z$ from a normal distribution with mean zero and variance $2 \sigma^{2}$.

\section{$\underline{\text { Stochastic Survival }}$}

The stochastic survival rates were modeled with mean $S_{\text {ef }}$ (Equation 32), $S_{1}$ (Equation 4), $S_{2}$ and $S$ (Table 2). Let $q$ denote any of these survival rates, then $0 \leq q \leq 1$ and $\operatorname{logit}(q)=\ln \left(\frac{q}{1-q}\right) \sim N\left(\operatorname{logit}(\mu), \sigma^{2}\right)$, where $\mu$ is the deterministic value of $q$. Although the variance of the survival rates is unknown, I can select a coefficient of variation to apply, so that $\sigma=\operatorname{logit}(\mu) \cdot C V$. I chose $C V=20 \%$ somewhat arbitrarily, but in other systems, this is a typical value for variability in environmentally determined demographic parameters (Van Kirk and Hill, 2007). Then the stochastic survival rate satisfies $\operatorname{logit}(q)=$ $\operatorname{logit}(\mu)+\epsilon$, where I select $\epsilon$ such that $\epsilon \sim N\left(0, \sigma^{2}\right)$ and algebraically solve for $q$.

For the selenium-dependent survival rate, I used Equation 24 with $\epsilon \sim N\left(0, \sigma^{2}\right)$, where $\sigma^{2}, a, b$ were estimated from data (Table 3 ).

Except for stochastic fluctuations, the population simulations over time reached equilibrium at approximately 15 years. Three simulations were executed with $S_{b}=1, S_{b}=$ $0.5, S_{b}=0.1$ to demonstrate model sensitivity to $S_{b}$. The simulations consisted of 1000 independent iterations of 25 years each and the dimensionless population size at year 25 was 
extracted as a proxy for the stochastic equilibrium size. This provided a random sample of independent equilibrium population sizes that could be observed under the given environmental variability. This was repeated for integer whole-body selenium concentrations $C=0-25 \mu \mathrm{g} / \mathrm{g}$. 


\title{
RESULTS AND DISCUSSION
}

\author{
Stochastic Results
}

The proxy equilibrium population size decreased monotonically as a function of selenium concentration for all simulations (Figure 8). The variability at $C=0 \mu g / g$ in Figure 8 represents the effects of background environmental variability associated with the stochastic parameters. Boxplots of the 1000 dynamic equilibrium population sizes at each concentration $(C=0-25 \mu \mathrm{g} / \mathrm{g})$ show the equilibrium size declining with increasing concentration and reductions were greater for $S_{b}=0.1$ (Figure 8). Population sizes exhibited greater variability after 25 years with $S_{b}=0.1$ and for larger toxin concentrations. Larger variability and declining population sizes resulted in more extinctions (Table 4). As the baseline first year survival decreased, the 25-year extinction probability increased considerably.

\section{Effects of Environmental Stochasticity}

Environmental variability results in population sizes that can be dramatically below the predicted deterministic size even for modest concentrations and high $S_{b}$ values. Extinctions

Table 4: Number of extinctions in 1000, 25 year simulations.

\begin{tabular}{cccc} 
Selenium concentration, $\mu g / g$ dry wt. & $S_{b}=1$ & $S_{b}=0.5$ & $S_{b}=0.1$ \\
\hline \hline 0 & 0 & 0 & 0 \\
10 & 0 & 0 & 0 \\
15 & 0 & 0 & 2 \\
20 & 0 & 0 & 8 \\
25 & 0 & 1 & 11 \\
\hline
\end{tabular}




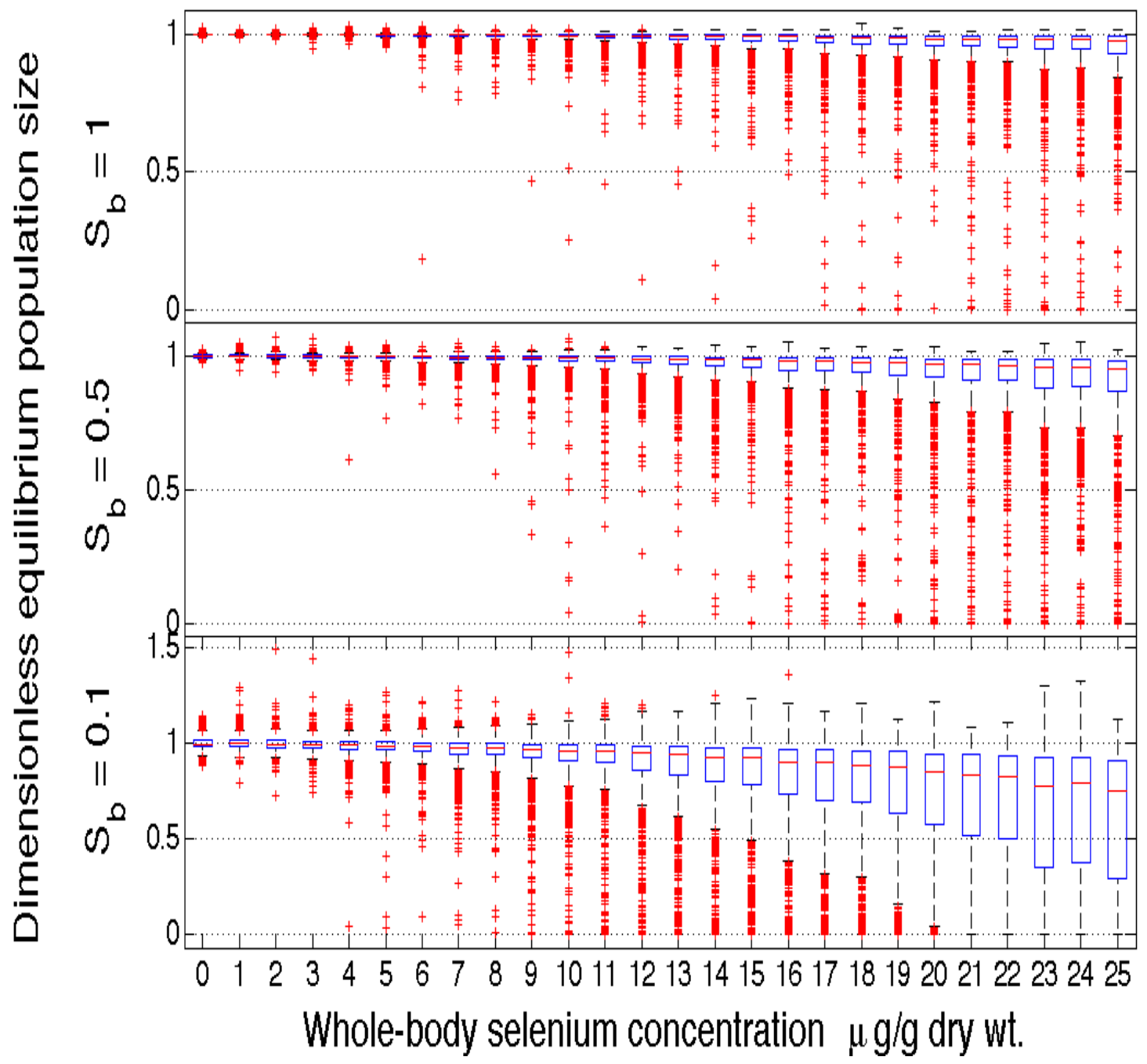

Figure 8: Simulation results. Each boxplot represents 1000 dimensionless population sizes after a 25 year simulation at a given concentration for $S_{b}=1, S_{b}=0.5, S_{b}=0.1$. 
can occur on short time horizons at concentrations well below those predicted from the deterministic analysis. For example, about $50 \mu \mathrm{g} / \mathrm{g}$ whole-body selenium concentration in dry weight will result in population extinction with $S_{b}=0.1$, deterministically. But the simulations experienced extinctions as low as $12 \mu \mathrm{g} / \mathrm{g}$, and the 25 -year extinction rate was over $1 \%$ with $25 \mu \mathrm{g} / \mathrm{g}$. Heightened extinction probabilities result from smaller populations which are more susceptible to random events, and linear PGR analysis will underestimate the population-level effect. Even if extinction does not occur, population sizes less than half the size of what the environment can support can be realized even with high $S_{b}$ and low concentrations.

The coefficient of variation used in the simulations was fixed at $20 \%$ as an example and may be quite low. Certainly larger $C V$ values will result in an increased effect of stochasticity with more frequent extinctions. In addition, the time frame used was rather short, fixed at 25 years. A more standard time horizon like 100 years would result in more extinctions.

\section{Relationship Between PGR and Equilibrium Population Size}

A goal of this research was to address the individual-to-population extrapolation problem by assessing the equilibrium size as a measure of population-level toxicity effect, in contrast to focusing on the population growth rate (PGR) to assess population-level toxicity.

The model in this research assumed an environmentally determined carrying capacity that limited population size in absence of toxicity. Each age class was scaled according to the total carrying capacity, so the dimensionless equilibrium population size is one. In absence of population-level toxicity effects, the equilibrium size is determined solely by the environment and not by additional mortality due to toxicity. Thus, in our model toxicity 
effects were measured as fractional reductions in the environmentally determined equilibrium size. When the population is limited by additional mortality due to toxicity, the equilibrium size is reduced, although the habitat can still support a larger population.

Whether the equilibrium size of a population is determined by the physical environment or by additional mortality due to toxicity, at equilibrium, the population is not growing, that is, the finite rate of growth is one. The population's intrinsic PGR in this model is directly related to the product $R S_{b}$, which does not change with additional toxicity-related mortality. Although $\lambda$ is not equal to $R S_{b}$, the condition $\lambda>1$ required for persistence is equivalent to the condition $R S_{b}>1$. With additional mortality due to toxicity, the potential for a population to grow at low densities is related to $R S_{b} S_{t o x}$. But $R S_{b} S_{t o x}(C) \leq R S_{b}$ and decreases as $S_{t o x}$ decreases. Thus the effects of toxicity on the PGR is reflected in $R S_{b} S_{t o x}$, and the corresponding condition for persistence is $R S_{b} S_{t o x}>1$.

The dimensionless equilibrium size (Equation 19) also depends on $R, S_{b}$ and $S_{t o x}$ and predicts extinction $(\tilde{E}(C)=0)$ if $R S_{b} S_{t o x} \leq 1$. The equilibrium size is a decreasing function of $S_{t o x}$ and hence toxin concentration $C$, even when the population persists (Figures 2 and 6). The size of the population may be reduced even when the PGR deterministically guarantees population persistence. Using the PGR as the sole endpoint to assess population-level toxicity misses the decline in population size due to toxicity since the PGR provides no measure of the size of the population. Finally, the PGR and the equilibrium size as population-level endpoints are related, but the equilibrium viewpoint provides more relevant and meaningful information about the effects of toxicity on a population. 


\section{Relationship Between Individual-Level and Population-Level Toxicity Response}

In our analysis, I defined the individual-level and population-level toxicity effect as mortality, $M_{t o x}=1-S_{t o x}$ and fractional reduction in equilibrium population size as $P(C)=$ $1-\tilde{E}(C)$, respectively. This relationship is depicted in Figure 1.

The population-level effect is smaller than the individual-level effect until the individual effect is large. This is due to density-dependent juvenile survival. Additional juvenile mortality due to toxicity results in fewer individuals competing for fixed resources; consequently, the density-dependent mortality decreases. Van Kirk and Hill (2007); Mebane and Arthaud (2010) also observed this compensatory phenomenon. A population can absorb some extra mortality before resulting in population-level effects for reasonable values of $R S_{b}$. The point at which population-level effects exceed individual effects depends on the recruitment potential $R S_{b}$. For large recruitment potential, individual mortality must be quite large for population-level effects to surpass individual effects; Van Kirk and Hill (2007) also observed this.

Effects on PGR are linear because $S_{\text {tox }}$ simply multiplies the intrinsic recruitment potential $R S_{b}$ to generate the toxicity-influenced recruitment potential $R S_{b} S_{t o x}$. However, the effect of toxicity on equilibrium population size is nonlinear (Equations 19 and 20), and this nonlinearity is most extreme at large recruitment potentials and low values of $S_{b}$ (Figures 1 and 7). Again, measuring effect of toxicity on PGR alone ignores the inherent nonlinearity of the system.

\section{Linking Population-Level Toxicity Response to Concentration}

Sigmoidal response curves are standard models to describe toxicity response, and I used variations on the logistic curve to describe toxicity response in this thesis. The logistic func- 
tion was a good model because of its desirable statistical properties. Because no additional mortality is expected with zero toxin concentration, and toxin concentrations are generally lognormally distributed, I expected the log-logistic function to be a better model than the traditional logistic model. When fit to bluegill-selenium toxicity data, the log-logistic function had a higher likelihood than the logistic function. Also, the log-logistic function reduces to a rational function of toxin concentration (Equation 24). When Equation 24 is substituted into the equilibrium population size (Equation 19), the result is a power relationship between the equilibrium size $\tilde{E}$ and toxin concentration $C$, in which the four key parameters are $L C_{50}, R, S_{b}$, and $b$. The $L C_{50}$ is the toxin concentration in which $50 \%$ of the experimental subjects die on average, $R S_{b}$ is the recruitment potential for a population, and $b$ is the rate at which individual mortality increases as a function of the logarithm of toxin concentration $C$. Figure 2 shows the dimensionless equilibrium population size as a function of dimensionless toxin concentration and illustrates the sensitivity to the slope parameter $b$.

\section{Sensitivity to $S_{b}$}

In practice, the reproductive potential $R$ of a fish population is straightforward to calculate from demographic data, but the density-independent first-year survival rate $S_{b}$ is not. In general, the reproductive potential $R$ probably varies with density in fish, but is not nearly as sensitive to density as $S_{b}$ (Quinn II and Deriso, 1999).

Thus, I assumed that the constituent functions of $R$-egg-to-fry survival, growth rate, adult survival, and maturation rate- are independent of density effects. Populations are rarely at low enough densities to measure the theoretical age 0-to-age 1 survival rate $S_{b}$. My application to bluegill fixed $R$ and varied $S_{b}$ to show how population persistence depended 
strongly on $S_{b}$ and was very sensitive when $S_{b}$ is near zero. I entertained the possibility that $S_{b}=1$, but that is very unlikely because some mortality will always occur even in an environment with theoretically infinite resources. Thus, $S_{b}$ is an important parameter to consider because effects of toxicity are underestimated by assuming that $S_{b}$ is near one.

\section{Comparison with Field Data}

Heightened concentrations of selenium have been identified in sections of the United States and throughout other parts of the world. Whole-body selenium concentrations in bluegill range from $0.43-51.64 \mu \mathrm{g} / \mathrm{g}$ dry weight in natural settings. Frequently observed wholebody selenium concentrations range from $0.6-4.1 \mu \mathrm{g} / \mathrm{g}$ (Ikem and Egilla, 2008; Reash et al., 2006; Burger et al., 2001; Nakamoto and Hassler, 1992; Saiki et al., 1992, 2001; Saiki and May, 1988). Extensive studies have been conducted in the San Joaquin River Valley, California to determine if elevated concentrations of contaminants are associated with agricultural drainwater. Concentrations of selenium in bluegill in the San Joaquin Valley range from $0.6-18 \mu \mathrm{g} / \mathrm{g}$ (Saiki et al., 2001). The mean selenium concentration of bluegill in the Savannah River, South Carolina and Georgia is $1.55 \mu \mathrm{g} / \mathrm{g}$ (Burger et al., 2001). Somewhat of a paradox is provided by the observations made by Reash et al. (2006) in southeast Ohio; Reash et al. (2006) reported a mean whole-body selenium concentration of $17.26 \mu \mathrm{g} / \mathrm{g}$ and range $6.15-51.64 \mu \mathrm{g} / \mathrm{g}$ in bluegill with no observed adverse effects on survival, teratogenesis, and reproductive failure. The results of this study contradicts previous reports showing population-level effects at much lower selenium concentrations than those found in southeast Ohio. An association between other trace metals have been observed to reduce the toxicity of selenium and other elements, and may provide a possible explanation for no evident population-level effects. But there is a lack of data to quantify 
a strong relationship (Reash et al., 2006). Concentrations as high as $50 \mu \mathrm{g} / \mathrm{g}$ (Reash et al., 2006) would certainly result in considerable population-level effects experiencing environmental stochasticity. But with high $S_{b}$ and minimal environmental variability, it is also possible to experience little population-level effects. In practice, though, it is difficult to measure a population-level response without knowing the carrying capacity and PGR for fish in absence of toxicity. Attempts to measure population-level effects of toxicity in the field should include a comparison of populations sizes and age-distributions with those of unexposed populations.

Experimental individual-level effect data often result in response data for low wholebody concentrations of $0-15 \mu \mathrm{g} / \mathrm{g}$, so I did not perform the bluegill simulations above $25 \mu \mathrm{g} / \mathrm{g}$ because the uncertainty would be too large for the model to be meaningful (Figure 4). Parameter estimates ( $b$ and $L C_{50}$ ) from experimental data critically determine how the equilibrium size declines with toxin concentration (Figure 2). Thus, more experimental data is needed to decrease the uncertainty in parameter estimates for the sigmoidal toxicity response curve. Van Kirk and Hill (2007) concluded that similar data deficiencies exist in modeling salmonid response to toxicity and thus that their population-level effects may have been underestimates.

Studies continue to support the whole-body selenium threshold of $4 \mu \mathrm{g} / \mathrm{g}$ for fish (Hamilton, 2003). Under my model, a whole-body selenium concentration of $4 \mu \mathrm{g} / \mathrm{g}$ would result in a $9.54 \%$ mean mortality response with $95 \%$ prediction range $0.65-63.13 \%$ (Figure 4). An average whole-body selenium concentration of $10.9 \mu \mathrm{g} / \mathrm{g}$ would impose an additional $50 \%$ mortality $\left(L C_{50}\right)$ to bluegill populations, according to our model. 


\section{Conclusions}

I developed an analytic framework to assess toxicity response at the population-level using the equilibrium size as the primary endpoint. Populations at equilibrium do not grow, that is, the actual finite rate of increase is one. Furthermore, when populations persist, the intrinsic finite rate is greater than one. Finally, the PGR provides no information about the size of the population, thus underestimating population-level effects. In general the populationlevel effect will be less than the individual-level effect until the individual effect is large under compensatory density-dependent survival. The parameters from experimental toxicity trials are essential to describe how rapidly the equilibrium size of a population responds to toxin concentration, and generally more data is needed to lessen the uncertainty in those parameter estimates. In addition the recruitment potential $R S_{b}$, particularly the first-year survival rate $S_{b}$ is an important parameter since population-level response is very sensitive to $S_{b}$. Assuming high first-year survival will severely underestimate the effects of toxicity on the equilibrium size of a population. The effects of environmental variability will result in extinctions at much lower toxin concentrations than predicted analytically. 


\section{BIBLIOGRAPHY}

Aday, D. D., C. M. Kush, D. H. Wahl, and D. P. Philipp. 2002. The influence of stunted body size on the reproductive ecology of bluegill Lepomis macrochirus. Ecology of Freshwater Fish, 11:190-195.

Allen, L. 2003. An Introduction to Stochastic Processes with Applications to Biology. Pearson Education Inc.

Bain, M. B. and L. A. Helfrich. 1983. Role of male parental care in survival of larval bluegill. Transactions of the American Fisheries Society, 112:47-52.

Belk, M. 1995. Variation in growth and age at maturity in bluegill sunfish: Genetic or environmental effects? Journal of Fish Biology, 47:237-247.

Belk, M. and S. Hales Jr. 1993. Predation-induced differences in growth and reproduction of bluegills Lepomis macrochirus. Copeia, 4:1034-1044.

Bennett, W. N., A. S. Brooks, and M. E. Boraas. 1986. Selenium uptake and transfer in an aquatic food chain and its effects on fathead minnow larvae. Archives of Environmental Contamination and Toxicology, 15(5):513-517.

Besser, J., T. Canfield, and T. W. La Point. 1993. Bioaccumulation of organic and inorganic selenium in a laboratory food chain. Environmental Toxicology and Chemistry, 12:5772 .

Besser, J., J. Giesy, R. Brown, J. Buell, and G. Dawson. 1996. Selenium bioaccumulation and hazards in a fish community affected by coal fly ash effluent. Ecotoxicology and Environmental Safety, 35:7-15.

Breck, J. 1996. Mechanisms of recruitment failure in bluegill ponds. Fisheries Research Report 2024, Michigan Department of Natural Resources.

Burger, J., K. Gaines, S. Boring, W. S. Jr., J. Snodgrass, and M. Gochfield. 2001. Mercury and selenium in fish from the Savannah River: Species, trophic level, and locational differences. Environmental Research Section, 87:108-118.

Calow, P., R. Sibly, and V. Forbes. 1997. Risk assessment on the basis of simplified lifehistory scenarios. Environmental Toxicology and Chemistry, 16:1983-1989.

Cardwell, R. D., D. G. Foreman, T. R. Payne, and D. J. Wilbur. 1976. Acute toxicity of selenium dioxide to freshwater fishes. Archives of Environmental Contamination and Toxicology, 4:129-144. 
Cedergreen, N., L. Andersen, C. F. Olesen, H. H. Spliid, and J. C. Streibig. 2005. Does the effect of herbicide pulse exposure on aquatic plants depend on kow or mode of action? Aquatic Toxicology, 71(3):261-271.

Cleveland, L., E. Little, D. Buckler, and R. Wiedmeyer. 1993. Toxicity and bioaccumulation of waterborne and dietary selenium in juvenile bluegill (Lepomis macrochirus). Aquatic Toxicology, 27:265-280.

Coyle, J., D. Buckler, C. Ingersoll, J. Fairchild, and T. May. 1993. Effect of dietary selenium on the reproductive success of bluegills (Lepomis macrochirus). Environmental Toxicology and Chemistry, 12(3):551-565.

Crawford, S. and M. Allen. 2006. Fishing and natural mortality of bluegills and redear sunfish at Lake Panasoffkee, Florida: Implications for size limits. North American Journal of Fisheries Management, 26:42-51.

DeAngelis, D., L. Svoboda, S. W. Christensen, and D. Vaughan. 1980. Stability and return times of Leslie matrices with density-dependent survival: applications to fish populations. Ecological Modelling, 8:149-163.

Dennis, B., P. Munholland, and J. Scott. 1991. Estimation of growth and extinction parameters for endangered species. Ecological Monographs, 61(2):115-143.

Dennis, B. and M. Taper. 1994. Density dependence in time series observations of natural populations. Ecological Monographs, 64(2):205-224.

Edelstein-Keshet, L. 2005. Mathematical Models in Biology. Society for Industrial and Applied Mathematics.

Edison, T. W., D. H. Wahl, M. J. Diana, D. P. Philipp, and D. J. Austen. 2006. Angler opinion of potential bluegill regulations on Illinois lakes: Effects of angler demographics and bluegills population size-structure. North American Journal of Fisheries Management, 26:800-811.

Eisler, R. 1985. Selenium hazards to fish, wildlife, and invertebrates: A synoptic review. Patuxent Wildlife Research Contaminant Hazard Reviews Report 5, U.S. Fish and Wildlife Service, Laurel, MD.

Ferson, S., L. Ginzburg, and R. Goldstein. 1996. Inferring ecotoxicological risk from toxicity bioassays. Water, Air and Soil Pollution, 91:71-82.

Finley, K. 1985. Observations of bluegills fed selenium-contaminated Hexagenia nymphs collected from Belews Lake, North Carolina. Bulletin of Environmental Toxicology, 35:816-825. 
Forbes, V. and P. Calow. 1999. Is the per capita rate of increase a good measure of population-level effects in ecotoxicology? Environmental Toxicology and Chemistry, 18(7):1544-1556.

Forbes, V., P. Calow, and R. Sibly. 2000. Are current species extrapolation models a good basis for ecological risk assessment? Environmental Toxicology and Chemistry, 20(2):442-447.

Garvey, J., T. Herra, and W. Leggett. 2002. Protracted reproduction in sunfish: The temporal dimension in fish recruitment revisited. Ecological Applications, 12(1):194-205.

Gatlin, D. and R. Wilson. 1984. Dietary selenium requirement of fingerling channel catfish. American Institute of Nutrition No. 5583.

Gerking, S. 1962. Production and food utilization in a population on bluegill sunfish. Ecological Monographs, 32(1):31-78.

Gillen, A., R. Stein, and R. Carline. 1981. Predation by pellet-reared tiger muskellunge on minnows and bluegills in experimental streams. Transactions of the American Fisheries Society, 110:197-209.

Gillespie, R. and P. Baumann. 1986. Effects of high concentrations of selenium on reproduction by bluegills. Transactions of the American Fisheries Society, 115:208-213.

Goodman, D. 1987. The demography of chance extinction. In M. Soule, ed., Viable Populations for Conservation, pp. 11-34. Cambridge University Press.

Gosch, N. J. C., Q. E. Phelps, and D. W. Gillis. 2006. Habitat characteristics at bluegill spawning colonies in a South Dakota glacial lake. Ecology of Freshwater Fish, 15:464469.

Gross, M. R. and A. M. Macmillan. 1981. Predation and the evolution of colonial nesting in bluegill sunfish (Lepomis macrochirus). Behavioral Ecology and Sociobiology, 8:163174.

Haddon, M. 2001. Modeling and Quantitative Methods in Fisheries. Chapman \& Hall/CRC.

Hamilton, S. 2003. Review of residue-based selenium toxicity thresholds for freshwater fish. Ecotoxicology and Environmental Safety, 56:201-210.

Hamilton, S. J., A. N. Palmisano, G. W. Wedemeyer, and W. T. Yasutake. 1986. Impacts of selenium on early life stages and smoltification of fall Chinook salmon. Transactions of the North American Wildlife and Natural Resources Conference, 51:343-356. 
Hamilton, S. J. and R. H. Wiedmeyer. 1990. Concentrations of boron, molybdenum, and selenium in Chinook salmon. Transactions of the American Fisheries Society, 119(3):500-510.

Hansen, F., V. Forbes, and T. Forbes. 1999. Using elasticity analysis of demographic models to link toxicant effects on individuals to the population level: an example. Functional Ecology, 13:157-162.

Henle, K., S. Sarre, and K. Wiegand. 2004. The role of density regulation in extinction processes and population viability analysis. Biodiversity and Conservation, 13:9-52.

Henry, T. B. and J. M. Grizzle. 2004. Survival of largemouth bass, bluegill and channel catfish embryos after electroshocking. Journal of Fish Biology, 64:1206-1216.

Hermanutz, R., K. Allen, T. Roush, and S. Hedtke. 1992. Effects of elevated selenium concentration on bluegills (Lepomis macrochirus) in outdoor experimental streams. Environmental Toxicology and Chemistry, 11:217-224.

Hilton, J. W., P. V. Hodson, and S. J. Slinger. 1980. The requirement and toxicity of selenium in rainbow trout (Salmo gairdneri). Journal of Nutrition, 110(12):2527-2535.

Ikem, A. and J. Egilla. 2008. Trace element content in fish feed and bluegill sunfish (Lepomis macrochirus) from aquaculture and wild source in Missouri. Food Chemistry, 110:301-309.

Kuhn, A., W. Munns, Jr., S. Poucher, D. Champlin, and S. Lusser. 2000. Prediction of population-level response from mysid toxicity test data using population modeling techniques. Environmental Toxicology and Chemistry, 19(9):2364-2371.

Lemly, A. 1985. Toxicology of selenium in a freshwater reservoir: Implications for environmental hazard evaluation and safety. Ecotoxicology and Environmental Safety, 10(3):314-338.

Lemly, A. 1993a. Guidelines for evaluating selenium data from aquatic monitoring and assessment studies. Environmental Monitoring and Assessment, 28:83-100.

Lemly, A. 1993b. Metabolic stress during winter increases the toxicity of selenium to fish. Aquatic Toxicology, 27:133-158.

Lemly, A. 1993c. Subsurface agricultural irrigation drainage: The need for irrigation. Regulatory Toxicology and Pharmacology, 17:157-180.

Lemly, A. 1997. Ecosystem recovery following selenium contamination in a freshwater reservoir. Ecotoxicology, 36:275-281. 
Lemly, A. 1998. Pathology of selenium poisoning in fish. In W. T. Frankenberger, Jr. and R. A. Engberg, eds., Environmental Chemistry of Selenium, chap. 16, pp. 281-296. Marcel Dekker.

Lemly, A. 1999. Selenium transport and bioaccumulation in aquatic ecosystems: A proposal for water quality criteria based on hydrological units. Ecotoxicology and Environmental Safety, 42:150-156.

Lemly, A. 2002. Symptoms and implications of selenium toxicity in fish: The Belews Lake case example. Aquatic Toxicology, 57:39-49.

Lincoln, R., G. Boxshall, and P. Clark. 1982. A dictionary of ecology, evolution, and systematics. Cambridge University Press.

Lohner, T. W., R. J. Reash, V. E. Willet, and L. A. Rose. 2001. Assessment of tolerant sunfish populations (Lepomis sp.) inhabiting selenium-laden coal ash effluents: 1. hematological and population level assessment. Ecotoxicology and Environmental Safety, 50(3):203-216.

Lopes, C., A. Péry, A. Chaumot, and S. Charles. 2005. Ecotoxicology and population dynamics: Using DEBtox models in a Leslie modeling approach. Ecological Modelling, 188:30-40.

Maas, J. 1998. Selenium metabolism in grazing ruminants: Deficiency, supplementation, and environmental implications. In W. T. Frankenberger, Jr. and R. A. Engberg, eds., Environmental Chemistry of Selenium, chap. 7, pp. 113-128. Marcel Dekker.

McIntyre, D., M. Pacheco, M. Garton, D. Wallschläger, and C. Delos. 2008. Effect of selenium on juvenile bluegill sunfish at reduced temperature. Tech. rep., Health and Ecological Criteria Division, Office of Water, U.S. Environmental Protection Agency, Washington, DC. Contract 68 C 04 006. EPA 822 R 08020.

Mebane, C. A. and D. L. Arthaud. 2010. Extrapolating growth reductions in fish to changes in population extinction risks: Copper and Chinook salmon. Human and Ecological Risk Assessment, 16(5):1026 - 1065.

Melbourne, B. A. and A. Hastings. 2008. Extinction risk depends strongly on factors contributing to stochasticity. Nature, 454:100-103.

Moyle, P. 2002. Inland Fishes of California. University of California Press.

Nakamoto, R. and T. Hassler. 1992. Selenium and other trace elements in bluegills from agricultural return flows in the San Joaquin Valley, California. Archives of Environmental Contamination and Toxicology, 22:88-98. 
Neff, B. D., P. Fu, and M. R. Gross. 2003. Sperm investment and alternative mating tactics in bluegill sunfish (Lepomis macrochirus). Behavioral Ecology, 14(5):634-641.

Neter, J., W. Wasserman, and M. H. Kutner. 1989. Applied Linear Regression Models. Irwin, 2nd ed.

Nriagu, J. 1989. Global cycling of selenium. In M. Ihnat, ed., Occurrence and Distribution of Selenium. CRC Press, Inc.

Ogle, R. S. and A. W. Knight. 1989. Effects of elevated foodborne selenium on growth and reproduction of the fathead minnow (Pimephales promelas). Archives of Environmental Contamination and Toxicology, 18:795-803.

Page, L. and B. Burr. 1991. A field guide to freshwater fishes of North America north of Mexico. Houghton Mifflin Company, Boston.

Panek, F. M. and C. R. Cofield. 1978. Fecundity of bluegill and warmouth from a South Carolina blackwater lake. The Progressive Fish Culturist, 40(2):67-68.

Parsons, B. G. and J. R. Reed. 1998. Angler exploitation of bluegill and black crappie in four west-central Minnesota lakes. Investigational Report 468, Minnesota Department of Natural Resources.

Paukert, C. P., D. W. Willis, and A. L. Glidden. 2001. Growth, condition, and mortality of black crappie, bluegill, and yellow perch in Nebraska Sand Hills lake. Great Plains Research: A Journal of Natural and Social Sciences, 11:261-274.

Quinn II, T. J. and R. B. Deriso. 1999. Quantitative Fish Dynamics. Oxford University Press.

Raisbeck, M. 2000. Selenosis. The Veterinary Clinics of North America, 16(3):465-480.

Ramsey, F. L. and D. W. Schafer. 2002. The Statistical Sleuth. Duxbury Thomson Learning.

Reash, R., T. Lohner, and K. Wood. 2006. Selenium and other trace elements in fish inhabiting a fly ash stream: Implications for regulatory tissue thresholds. Environmental Pollution, 142:397-408.

Rotruck, J. T., A. L. Pope, H. E. Ganther, A. B. Swanson, D. G. Hafeman, and W. G. Hoekstra. 1973. Selenium: Biochemical role as a component of glutathione peroxidase. Science, 179(4073):588-590.

Saiki, M., M. Jennings, and T. May. 1992. Selenium and other elements in freshwater fishes from the irrigated San Joaquin Valley, California. The Science of the Total Environment, 126: $109-137$. 
Saiki, M., B. Martin, S. Schwarzbach, and T. May. 2001. Effects of agricultural drainwater bypass on fishes inhabiting the Grassland Water District and the Lower San Joaquin River, California. North American Journal of Fisheries Management, 21:624-635.

Saiki, M. and T. May. 1988. Trace element residues in bluegills and common carp from the Lower San Joaquin River, California, and its tributaries. North American Journal of Fisheries Management, 74:199-217.

Sammons, S. and M. Maceina. 2009. Variation in growth and survival of bluegills and redbreast sunfish in Georgia rivers. North American Journal of Fisheries Management, 29:101-108.

Sammons, S. M., D. G. Partridge, and M. J. Maceina. 2006. Differences in population metrics between bluegill and redear sunfish: Implications for the effectiveness of harvest restrictions. North American Journal of Fisheries Management, 26:777-787.

Santucci, Jr., V. J. and D. H. Wahl. 2003. The effects of growth, predation, and first-winter mortality on recruitment of bluegill cohorts. Transactions of the American Fisheries Society, 132:346-360.

Schneider, J., P. Laarman, and H. Gowing. 2000. Age and growth methods and state averages. In J. Schneider, ed., Manual of fisheries survey methods II: with periodic updates, Michigan Department of Natural Resources, Fisheries Special Report 25, chap. 9. Ann Arbor.

Schneider, J. and R. Lockwood. 1997. Experimental management of stunted bluegill lakes. Fisheries Special Report 2040, Michigan Department of Natural Resources.

Skorupa, J. P. 1998. Selenium poisoning of fish and wildlife in nature: Lessons from twelve real-world examples. In W. T. Frankenberger, Jr. and R. A. Engberg, eds., Environmental Chemistry of Selenium, chap. 18, pp. 315-354. Marcel Dekker.

Spromberg, J. A. and W. J. Birge. 2005. Modeling the effects of chronic toxicity on fish populations: The influence of life-history strategies. Environmental Toxicology and Chemistry, 24(6):1532-1540.

Spromberg, J. A. and J. P. Meador. 2005. Relating results of chronic toxicity responses to population-level effects: Modeling effects on wild Chinook salmon populations. Integrated Environmental Assessment and Management, 1(1):9-21.

Spromberg, J. A. and J. P. Meador. 2006. Relating chronic toxicity responses to populationlevel effects: A comparison of population-level parameters for three salmon species as a function of low-level toxicity. Ecological Modelling, 199(3):240-252. 
Stark, J. 2005. How closely do acute lethal concentration estimates predict effects of toxicants on populations? Integrated Environmental Assessment and Management, 1(2):109-113.

Stark, J. and J. Danken. 1999. Importance of population structure at the time of toxicant exposure. Ecotoxicology and Environmental Safety, 42:282-287.

Stark, J. and R. Vargas. 2003. Demographic changes in Daphnia pulex (leydig) after exposure to the insecticides spinosad and diazinon. Ecotoxicology and Environmental Safety, 56:334-338.

Strogatz, S. H. 1994. Nonlinear Dynamics and Chaos. Perseus Books Publishing, LLC.

Swift, M. C. 2002. Stream ecosystem response to, and recovery from, experimental exposure to selenium. Journal of Aquatic Ecosystem Stress and Recovery, 9:159-184.

Tomcko, C. M. and D. Pereira. 2006. The relationship of bluegill population dynamics and submerged aquatic vegetation in Minnesota lakes. Investigational Report 538, Minnesota Department of Natural Resources.

USEPA. 1987. Ambient water quality criterion for selenium-1987.

USEPA. 2006. National recommended water quality criteria. URL http://www.epa.gov/waterscience/criteria/wqctable/.

Van Kirk, R. and S. Hill. 2007. Demographic model predicts trout population response to selenium based on individual-level toxicity. Ecological Modelling, 206:407-420.

Walthall, W. K. and J. D. Stark. 1997. Comparison of two population-level ecotoxicological endpoints: The intrinsic $\left(r_{m}\right)$ and instantaneous $\left(r_{i}\right)$ rates of increase. Environmental Toxicology and Chemistry, 16(6):1068-1073.

Woock, S., W. Garrett, W. Partin, and W. Bryson. 1987. Decreased survival and teratogenesis during laboratory selenium exposures to bluegill, Lepomis macrochirus. Bulletin of Environmental Contamination and Toxicology, 39:998-1005.

Zhang, Y. and J. Moore. 1998. Selenium accumulation in a wetland channel, Benton Lake, Montana. In W. T. Frankenberger, Jr. and R. A. Engberg, eds., Environmental Chemistry of Selenium, chap. 14, pp. 243-257. Marcel Dekker. 